NBER WORKING PAPER SERIES

\title{
EXPERIMENTAL EVIDENCE ON THE EFFECT OF INFORMATION AND PRICING ON RESIDENTIAL ELECTRICITY CONSUMPTION
}

\author{
Jesse Burkhardt \\ Kenneth Gillingham \\ Praveen K. Kopalle \\ Working Paper 25576 \\ http://www.nber.org/papers/w25576 \\ NATIONAL BUREAU OF ECONOMIC RESEARCH \\ 1050 Massachusetts Avenue \\ Cambridge, MA 02138 \\ February 2019
}

The authors are grateful for conversations and comments from seminar participants at Yale, UC Berkeley, ETH Zurich, Georgia State, CU-Boulder, Georgetown University, Dartmouth College, McMaster University, Indian School of Business, ACR Conference, Marketing Science Conference, and the AMA-Sheth Doctoral Consortium as well as comments from Dave Rapson, Koichiro Ito, Matt Harding, Rob Metcalfe, Matt Kotchen, Brian Prest, and Severin Borenstein. The authors would also like to thank the staff at the Pecan Street, and especially Grant Fisher. The views expressed herein are those of the authors and do not necessarily reflect the views of the National Bureau of Economic Research.

NBER working papers are circulated for discussion and comment purposes. They have not been peer-reviewed or been subject to the review by the NBER Board of Directors that accompanies official NBER publications.

(C) 2019 by Jesse Burkhardt, Kenneth Gillingham, and Praveen K. Kopalle. All rights reserved. Short sections of text, not to exceed two paragraphs, may be quoted without explicit permission provided that full credit, including $(\odot$ notice, is given to the source. 
Experimental Evidence on the Effect of Information and Pricing on Residential Electricity

Consumption

Jesse Burkhardt, Kenneth Gillingham, and Praveen K. Kopalle

NBER Working Paper No. 25576

February 2019

JEL No. D83,L94,L98,Q41,Q48

\section{ABSTRACT}

This study examines a field experiment in Texas that includes pricing and informational interventions to encourage energy conservation during summer peak load days when the social cost of generation is the highest. We estimate that our critical peak pricing intervention reduces electricity consumption by $14 \%$. Using unique high frequency appliance-level data, we can attribute $74 \%$ of this response to air conditioning. In contrast, we find minimal response to active information provision and conservation appeals. A complementary experimental program also lowers nighttime prices during the off-peak season, providing the first evidence of electric vehicle loadshifting in response to price.

Jesse Burkhardt

Colorado State University

1200 Center Ave. Mall

Fort Collins, CO 80523

jesse.burkhardt@colostate.edu

Kenneth Gillingham

School of Forestry and Environmental Studies

Yale University

195 Prospect Street

New Haven, CT 06511

and NBER

kenneth.gillingham@yale.edu
Praveen K. Kopalle

Tuck School of Business

Dartmouth College

Hanover, NH 03755

United States

kopalle@dartmouth.edu 


\section{Introduction}

A central question in economics is how information influences consumer decisions. A growing literature has demonstrated that consumers face information costs, such that the simple conveyance of information can dramatically change behavior. Consumers reduce their use of mobile phone minutes when told they are reaching the next pricing tier (Grubb and Osborne 2015), employees change their retirement plans when given information on benefits (Duflo and Saez 2003), and residential households are influenced by simple social comparison messages in their use of electricity and water (Allcott 2011b; Ferraro and Price 2013; Allcott and Rogers 2014). Information provision interventions often aim to influence behavior based on pro-social motives, pecuniary motivations, or some combination. ${ }^{1}$ For example, conservation appeals can reduce electricity use during times of crisis (Ito et al. 2018; Reiss and White 2008), while Brandon et al. (2018) show that social nudges can reduce peak electricity usage and Jessoe and Rapson (2014) show that high-frequency electricity usage information increases price responsiveness during peak events.

Based on this growing evidence, policymakers are often drawn to information-based approaches as politically palatable ways to reduce residential electricity consumption during critical peak times. From a political feasibility perspective, such informationbased approaches are advantageous in that they do not require changing prices the way that dynamic pricing approaches do. However, dynamic pricing approaches, such as critical peak pricing or real-time pricing, more directly align retail prices with wholesale prices, but both information and pricing have the potential to allow demand to respond during times when the social cost of electricity provision is very different than the retail price. In this sense, both may be effective in improving the economic efficiency of electricity markets (Borenstein and Holland 2005), and indeed the rational choice model implies that full information is required for an optimal response to pricing (e.g., Rosen 1974).

\footnotetext{
${ }^{1}$ Indeed, there is even a literature in behavioral economics on whether extrinsic incentives (e.g., external rewards) crowd out intrinsic motivations (e.g., pro-social or altruistic motivations) (Gneezy et al. 2011)
} 
In this study, we examine a field experiment in Austin, Texas designed to improve our understanding of the consumer response to information and pricing in electricity consumption. ${ }^{2}$ There are two programs in our field experiment. A summer program tests how information provision and conservation appeals compare to critical peak pricing during 27 of the hottest days over two summers, when the wholesale price of electricity is substantially above the retail tariff. An off-peak program tests for an asymmetric pricing response and electric vehicle load-shifting by offering lower marginal prices of electricity during the night in off-peak months, when the wholesale price of electricity is below the standard retail tariff due to high production from West Texas wind facilities. A novel feature of this study is that we not only observe minute-level electricity consumption, but we also observe electricity consumption by key appliances, providing deeper insight into the mechanisms underpinning the consumer response to informational and pricing interventions designed to improve economic efficiency.

Our first major result is that informed consumers clearly respond to both increases and decreases in the marginal price of electricity, but show minimal response to the provision of information or conservation appeals alone. Our critical peak pricing intervention reduces electricity use by $14 \%$. The informational interventions in our study are the following: an online portal, a text message conservation appeal, and a text message with suggestions for concrete actions. This finding of a minimal response to information notably contrasts with previous literature. For example, Ito et al. (2018) and Reiss and White (2008) demonstrates short-term effects of conservation appeals (moral suasion) in reducing electricity consumption during crisis periods. However, our empirical setting covers typical summer days rather than times of crisis. It also differs from Brandon et al. (2018), who show that pre-event phone calls, along with OPower social comparison home energy reports and post-event phone calls, can lead to a $6.8 \%$ decrease in electricity use. Thus, we view our results as suggesting that outside of crisis periods, price changes have the potential to provide much larger reductions in electricity consumption than standard text message or email information treatments, while more intensive information interventions

\footnotetext{
${ }^{2}$ In the nomenclature of Harrison and List (2004), our study is of a "framed field experiment."
} 
may still be effective.

We also present evidence of a longer-run response to the pricing intervention that is consistent with previous estimates of consumer learning via in-home devices (Jessoe and Rapson 2014) and habituation to conservation appeals (Ito et al. 2018). The critical peak period in our experiment runs from 4-7 PM, and we observe persistence in electricity reductions in the two hours just after $7 \mathrm{PM}$, with the strongest effect in the 30 minutes just after the end of the treatment. We further explore the possibility of habituation to the pricing treatment, and find that the treatment effects dissipate somewhat over time across the two summers of the experiment.

Another contribution of our paper is to provide the first well-identified evidence of load-shifting from lower prices of electricity use at night, and to show that the source of this load shifting is largely from electric vehicle owners programming their vehicles to charge late at night. This result is new to the literature and holds promise for policies to improve economic efficiency by lowering nighttime electricity prices. We find virtually no evidence of load-shifting from changes in prices during critical peak periods, consistent with the results in Allcott (2011a). Similar to Harding and Lamarche (2016), we find some evidence of load-shifting for households with programmable thermostats, but the load shifting due to electric vehicles far exceeds the load shifting from programmable thermostats.

Our unique household appliance-level data provide a further contribution. We find that $74 \%$ of the total response to the critical peak pricing experiment can be attributed to changes in air conditioning use. For comparison, air conditioning constitutes $63 \%$ of the load on average during event periods, so this is a greater than proportional response by air conditioning. Aside from air conditioning, the response to pricing comes about from a variety of sources and no other single source dominates. Taken in context of our results showing that the treatment effects of pricing dissipate over time, this implies that the pricing scheme is working on the intensive margin through effort, rather than influencing households to adopt energy-efficient technologies. This result differs from the result in 
Brandon et al. (2017) indicating that the majority of the effect of OPower Home Energy Reports comes from adoption of new technologies.

The results of this study have several policy implications. Besides suggesting that information-only interventions are less effective than pricing interventions during typical summer peak periods, they also provide new evidence of the effectiveness of reducing prices during low wholesale price periods. We are unaware of any previous work performing such an experiment lowering prices at night and the degree of load-shifting we find demonstrates the effectiveness of this pricing policy. By showing that $74 \%$ of the total response to critical peak pricing comes from air conditioning, our results also indicate that critical peak pricing acts a substitute for automatic control of air conditioning, indicating reduced effectiveness if the two policies are used in concert.

One key aspect of the field experiment is that it was conducted in an empirical setting with a relatively high penetration of electric vehicles, and thus provides foresight into a likely future in which the transportation sector and electricity grid are more closely interlinked. This aspect also implies that some of the results, such as the off-peak lowerpricing results, should not be directly applied to other neighborhoods today with much lower penetration of electric vehicles, but will become increasingly relevant in the near future. More broadly, we believe that our results provide useful insights for understanding consumer behavior in similar neighborhoods throughout the south and southwestern United States with similar hot days as in Austin, while they are less useful for areas with very different climates and households.

The remainder of the paper is organized as follows. In the next section, we begin by presenting our experimental design and hypotheses. Section 3 presents the data, along with descriptive model-free evidence of the treatment effects. Section 4 provides our empirical analysis and results and section 5 discusses the welfare implications of our results. Section 6 concludes. 


\section{Research Design}

\subsection{Experimental Design}

The two programs of our field experiment were conducted in 2013 and 2014 in Austin, Texas. The non-profit "Pecan Street, Inc." is our collaborator and data provider. ${ }^{3}$ Pecan Street has developed relationships with hundreds of households within the Mueller neighborhood of Austin, Texas to monitor their energy use, much as a utility would monitor energy use. Thus, the focus of our study is on the Mueller neighborhood, which we will discuss in more detail below.

Pecan Street began recruiting households into the study in early 2013 using their preexisting Mueller neighborhood and Austin-wide e-mail lists. Households were told that by enrolling they could save on their electric bills, and were provided a $\$ 200$ sign-up incentive for participating regardless of their behavior. The recruitment e-mails also were clear that there was no possibility of a loss (see Appendix A for the e-mail text). The recruitment was highly successful and 280 households that agreed to participate were included in the experiment. ${ }^{4}$ All but 24 of the households in the study were from the Mueller neighborhood. Thus, this study is akin to nearly all of the recent field experiments on electricity consumption in being a randomized controlled trial for self-selected participants (e.g., Wolak 2013, 2011; Jessoe and Rapson 2014; Ito et al. 2018). As such, our research design assures internal validity of the study and we carefully discuss the external validity of the study for proper interpretation of the findings.

The primary reason for the relatively small sample size is that all 280 households in the study had appliance-level electric meters installed on major appliances and circuitlevel meters for rooms that did not have major appliances. For the 256 households in the Mueller neighborhood, these were installed upon construction of the homes. For

\footnotetext{
${ }^{3}$ Pecan Street is an Austin-based non-profit affiliated with UT-Austin founded in 2008 dedicated to building a deeper understanding of energy and water use through systematic monitoring and measuring of consumption behavior. See https:/ / www.pecanstreet.org/about/ for more details on Pecan Street.

${ }^{4}$ Another 44 households from the Mueller neighborhood were also enrolled in a Nest experiment at the same time through the same recruitment process, but we do not examine this treatment arm in this paper in order to keep this analysis focused.
} 
the 24 households elsewhere in Austin, these were installed upon participation in any Pecan Street activity (all prior to this experiment). The 256 households in the Mueller neighborhood were randomly assigned to one of five groups:

1. Control - 57 homes did not receive any treatment during 2013 and 2014. Like the other groups, they also had appliance-level and circuit-level metering.

2. Passive Information - 44 homes were provided access to an online portal that tracks appliance-level electricity use. ${ }^{5}$

3. Active Information - 46 homes were sent a text message appeal 24 hours prior to every critical peak pricing event stating "A Pecan Street Project critical peak event is taking place tomorrow from 4 PM to 7 PM."

4. Active Information + Recommendation -47 homes received the same text message with one of three recommended actions: "Pre-cool your home," "Reduce your air conditioning usage," or "Do not use your clothes dryer."

5. Pricing - 62 homes faced critical peak pricing during the summer months (JuneSeptember) of 2013 and 2014. They received a text message 24 hours prior to each event stating "Tomorrow is a Critical Peak Pricing event. Your experimental electric rate will be $\$ 0.64$ per kilowatt hour from 4 PM - 7 PM. Pecan Street Inc. Pricing." During the months of March, April, May, November, and December, when wholesale prices at night are low, they received a text message 24 hours prior to the start of the nighttime pricing stating, for example "Pricing Trial Reminder: November and December are wind enhancement months." The lower experimental price was 2 cents/kWh. ${ }^{6}$

\footnotetext{
${ }^{5}$ Each participant had access to an online portal. For the portal treatment group, this was the only treatment. The portal displayed monthly whole home energy use in $\mathrm{kWh}$, monthly energy costs in dollars per appliance, energy generation cost in dollars if the participant had solar panels, real-time energy consumption in $\mathrm{kWh}$, monthly energy cost comparison to other participants within the same zip code, and monthly energy usage trends.

${ }^{6}$ The pricing group received a text message one day prior to the beginning of each wind night pricing month.
} 
For the average customer, the Austin Energy summer (June-September) electric rate in 2013 was 11.4 cents/kWh and in 2014 was 12.1 cents/kWh. In the winter (October-May) it was 8.7 cents $/ \mathrm{kWh}$ in 2013 and 8.9 cents $/ \mathrm{kWh}$ in 2014. Thus, the pricing trial led to a substantially higher marginal price during the peak event periods and a substantially lower marginal price during the night wind event periods. ${ }^{7}$ Twenty-seven critical peak treatment days occurred during the months of June through September 2013 and 2014. All treated participants (i.e., the information groups and the pricing group) were sent an e-mail upon their registration indicating that they could save money during peak times by shifting laundry, dishwashing, and air conditioning usage to another time.

The randomization occurred once and was used for both programs of the field experiment: the summer critical peak pricing program and the winter lower pricing program. In effect, the households in the pricing trial had their wholesale tariffs moved closer to wholesale prices in both the off-peak and summer months. The sample size of this experiment is relatively small by necessity due to the cost and challenge of ensuring appliancelevel meters in all households, which is a critical part of the study. Fortunately, previous work on critical peak pricing suggested reasonably large treatment effects, and thus we had reason to believe that we would have sufficient statistical power.

One challenge in the experimental design is that only electric utilities have the ability to change electricity rates. Pecan Street has a relationship with customers just like the utility, but is not the actual utility, which is Austin Energy. Thus, to change the marginal price for consumers, we followed the same approach as in several recent papers, including Wolak (2006) and Gillian (2018). Specifically, Pecan Street set up a credit account for each household in the pricing trial, which they could view on the online portal. The household receives their usual electric bill from Austin Energy, but will also receive a modified bill from Pecan Street. If the bill using the experimental critical peak pricing rate was lower than participant's Austin Energy bill, the difference is deposited in the credit account. If the bill using the experimental rate was higher, the difference was deducted from the account. At the end of both pricing experiments in October 2014, participants were issued

\footnotetext{
${ }^{7}$ Appendix A.1 includes more details on the Austin Energy rates and experimental rates.
} 
a payment.

We recognize that if there are behavioral biases, the effect of this payment scheme may not exactly match the effects of critical peak pricing performed by the utility that directly changes the single electricity bill. Pecan Street attempted to mitigate this as much as possible by communicating the critical peak prices in the text message and by emphasizing in e-mail communications that the household's true electric bill is the Pecan Street bill. At the end of the experiment, $97 \%$ of the pricing participants had positive credits, implying that they saved money from their actions under the experiment. The average payment was $\$ 125.13$ and the highest payment was $\$ 260$, plus the $\$ 200$ flat-rate participation payment that all participants in all treatment groups received (so the largest overall payment was $\$ 460){ }^{8}$ If households pay more attention to their credit balance than to the clear guidance from Pecan Street on what their true electricity bill is, then it is possible that a bias such as loss aversion could influence the results (Kahneman and Tversky 1984). Such a bias would suggest that people who actually faced critical peak pricing, rather than receiving the credit, would respond even more to pricing than the households in our experiment.

There is one very useful aspect of the payment scheme we use. While it may not exactly match critical peak pricing by the utility, it is also likely to be more politically feasible than critical peak pricing, which often faces barriers in public utility commission hearings. Some consumer advocate groups are opposed to critical peak pricing, for they see it as another way to raise electric rates. By creating a higher marginal rate during critical peak event periods through a credit account, households can only be made betteroff. As we will discuss in the welfare section, critical peak pricing lowers the cost of electricity provision by shaving the peaks, so it is possible that there is a realized Pareto improvement in this policy design (still second-best of course). Consumers are better off from the compensation through the credit account, while at the same time there is an improvement in economic efficiency from reducing peak electricity demand.

\footnotetext{
${ }^{8}$ Note that the payment was not until after the trial and generally participants in the experiment are reasonably well-off, so do not anticipate weak separability with the level of income being violated.
} 
Our experimental setting-the Mueller neighborhood of Austin-is a large neighborhood of about 15,000 people in 5,100 single-family, condo, or apartment homes. In 1999 the Robert Mueller Municipal Airport was closed and planning began on the roughly one-square mile plot for a mixed residential commercial, and retail development. The development was designed to be mixed-income. The first homes were completed in 2008 and Pecan Street began that year with continuous monitors of electricity and water consumption in the new homes. Allcott (2015) finds evidence of a "site selection bias" in the effects of OPower home energy reports due to observable and unobservable characteristics across different locations, and thus is is worth considering how representative the Mueller neighborhood is of the city of Austin. In Appendix A, we compare Census demographic data from 2014 for the Mueller neighborhood and the city of Austin (see Table A.1).

Our comparison of observables indicates that the Mueller neighborhood is quite similar to the average in the city of Austin. In fact, the confidence intervals overlap in five of the eight observables. There are some minor differences. Households in the Mueller neighborhood are very slightly wealthier and better-educated than households in Austin as a whole. Not surprisingly, because the homes are relatively new, the median home value for owner-occupied housing units is higher than average in the city of Austin. However, the number of rooms in the homes is slightly smaller. While it is always impossible to fully rule out site selection bias without performing multiple studies, the additional 24 households included from outside the Mueller neighborhood provide some further evidence on the external validity to the rest of Austin. We are very cautious in extrapolating our results too far beyond Austin, but believe that they provide useful information on other settings in the south and southwestern parts of the United States that have similar climates and demographics. 


\subsection{Hypotheses}

The treatments in this study were designed to include passive provision of information as well as increasingly active provision of information and pricing. As described in the introduction, there is a broad literature showing that consumers respond to information in a variety of settings. Several papers point out that simply providing access to information about electricity consumption can influence consumer behavior. For example, Martin and Rivers (2018) present evidence from a field experiment that providing an in-home device that gives households real-time feedback on electricity consumption and prices leads households (who are already on time-of-use pricing) to reduce electricity consumption by $3 \%$. Byrne et al. (2018) show heterogeneous effects of high-frequency feedback and peer comparisons, with some households consuming less and others consuming more. Several papers show that an in-home device can enhance the response to pricing (Martin and Rivers 2011; Jessoe and Rapson 2014; Bollinger and Hartmann 2018).

This study uses an online portal to provide passive information-households must actively choose to look at the online portal on their computer or phone. A few studies have used online portals along with other interventions aiming to influence electricity use (Asensio and Delmas 2015; Bollinger and Hartmann 2018), but we are not aware of any study that tests for the effect of an online portal itself. We view the online portal as similar to an in-home device, but a more passive approach. Thus, a first hypothesis is that there may be a modest response to providing consumers with access to an online portal.

There is more evidence directly related to our active information treatments for household energy consumption. For example, Ito et al. (2018) show that text message conservation appeals (focusing on intrinsic motivation) lead to conservation of energy during critical peak events in Japan during the time of the Fukushima Daiichi nuclear crisis, although there is some habituation to this effect. Reiss and White (2008) show that broad-based media campaigns led to conservation during the California electricity crisis. Asensio and Delmas (2015) show reductions in electricity use from health and environmental-based appeals for college students in a UCLA housing complex who had access to an online 
portal and received messages through this portal. All of this evidence suggests that a text messages designed to make the event periods salient should reduce electricity consumption. ${ }^{9}$ Accordingly, our second hypothesis is that we will see a reduction in electricity use from text message conservation appeals.

Further, there is growing work indicating that OPower Home Energy Reports, which include a social norms message along with suggested concrete actions, can also reduce electricity usage (Allcott 2011b; Allcott and Rogers 2014). While the work on OPower does not disentangle the effect of these concrete actions from social norms, it seems reasonable to expect that concrete recommendations in addition to text messages may not only direct the energy conservation to certain appliances, but also lead to greater reductions in overall energy use. Hence, our third hypothesis is that when given text messages along with recommendations of concrete actions, households will reduce electricity consumption even more than simple text message conservation appeals, and the reductions may even be directed at specific end-uses.

There is also a growing literature on the household response to different types of dynamic pricing in different settings. Harding and Sexton (2017) provide a recent review of this literature. Key findings in the review are that households do tend to respond to critical peak pricing, especially when they are informed about it. But peak pricing demand elasticities are generally low, with price elasticities around -0.1. Recent work by Gillian (2018) and Prest (2018) further suggests that the price response may be quite insensitive to the price change, so that the percent reduction in electricity consumption is similar for large and small changes in the price. Explanations for this include households using simplifying heuristics (e.g., noting a change in price, but not paying attention to the price level) and households being partly inattentive. Our study does not focus on the response to different price levels, but does examine a large price increase. Previous studies have found that price increases of a similar magnitude lead to a reduction in electricity use (Wolak 2006, 2013; Jessoe and Rapson 2014; Ito et al. 2018). Ito et al. (2018) also shows that

\footnotetext{
${ }^{9}$ Brandon et al. (2018) show that phone calls along with OPower social norms mailings-a more active intervention-can reduce electricity usage during peak periods.
} 
the response to price is much greater than the response to text messages in the Japanese context. Therefore, our fourth hypothesis is that we will see a reduction in electricity use from our critical peak pricing treatment, and that this effect will be larger than the effect from information.

While there is substantial evidence available on critical peak pricing, there is little evidence available to inform hypotheses about our night off-peak program part of the experiment. There are plenty of estimates of price elasticities identified from variation that includes both negative and positive price changes, so we might expect some change in electricity usage. Of course, electricity use at night is different than electricity use in the day. With nearly all appliances either off or running all the time (such as refrigerators), one might expect a very inelastic response at night. Yet many previous studies did not involve homes with programmable thermostats and electric vehicles that can be programmed to charge at different times. As mentioned above, Harding and Lamarche (2016) find load shifting from households with programmable thermostats, suggesting that we should expect to see some changes in electricity use. Thus, our final hypothesis is that the low price treatment will lead to some load shifting from daylight hours to night hours, improving economic efficiency.

\section{Data and Descriptive Evidence}

\subsection{Data}

The primary outcome variable in our study is electricity consumption. We have unique minute-appliance-level electricity consumption data for each household from March 2013 through October 2014..$^{10}$ Appliances that are separately metered include HVAC and other air conditioning units, refrigerators, electric vehicle chargers, clothes washers and dryers, dishwashers, ovens, and electric water heaters. In addition to the separate appliances,

\footnotetext{
${ }^{10}$ Asensio and Delmas (2015) is the only other paper we are aware of using minute-appliance-level electricity consumption data for a large sample of households; however, their sample consists of UCLA students in a housing complex, rather than the residents of a neighborhood.
} 
circuit-level meters are also included when there are circuits for specific rooms. For example, there are readings for bedrooms, kitchens, and bathrooms. Our data also contain a variable for total electricity consumption, which may include some electricity usage that is not individually metered. There are roughly 200 million observations in our dataset. Before performing any analyses, we conduct some minor data cleaning (see Appendix B.1 for details).

Table 1 presents a summary of electricity usage data by period: summer (JuneSeptember), non-summer (all other months), and the summer critical peak pricing periods. We have minute-level data in units of kWh per hour. In Panel A we divide observed appliance-level electricity consumption into two broad categories: adjustable consumption and unadjustable consumption. Adjustable consumption refers to sources that are likely to be easily switched up and down. For example, air conditioning, clothes washing and drying, etc. In non-summer periods, this is just under $40 \%$ of electricity consumption on average, but it increases to $58 \%$ of consumption in the summer and $73 \%$ of consumption during event periods. Unadjustable consumption refers to sources that run all the time, such as refrigerators. In non-summer months, this makes up $8 \%$ of consumption, but it drops to $5 \%$ in the summer months and to $4 \%$ during event periods. As mentioned above, not all electricity usage is individually metered. Thus, we have a third category for unmeasured electricity consumption, which is equal to the total electricity consumption minus the sum of the measured consumption. In non-summer months, this is over $50 \%$ of consumption, as might be expected due to the many small appliances in a typical household (e.g., computers, phone chargers, hair dryers, electric tools, etc.). In summer periods, this drops to $37 \%$ and in event periods it drops further to $23 \%$. The three categories sum up to $100 \%$.

In Panel B of Table 1, we include four of the most important individually metered uses. For context, not all households have each of the uses (although each use is metered when houses have it) and these averages are taken over all households in our sample. Nearly all households have heating and cooling technologies individually metered. In the winter, 
this is primarily natural gas heating, with electricity used to run the fan. In the summer, it is all air conditioning. The data contain consumption for central air conditioning as well as window units, and we aggregate these together into a single " $\mathrm{AC}$ " variable. We see that in the non-summer months, heating and cooling constitutes $16 \%$ of electricity use, while in the summer months it constitutes $45 \%$ of electricity use, and during event days it reaches $63 \%$ of electricity use. In contrast, washers and dryers constitute 3\% of electricity use in the non-summer months, and less than $2 \%$ during the summer or event days. These summary statistics provide a glimpse into the unusually rich nature of our data and illustrate how heating and cooling are the most important electricity service demands. For the $36 \%$ of households in the pricing and treatment groups that have electric vehicles, the percentage of EV electricity consumption (by minute) is $5.7 \%$.

Next, we examine the balance of observables between the control group and the treatment groups to assure that our randomization was carried out effectively. For this, we relied on a survey of all households performed at the beginning of the experiment. Of the 280 households in the experiment, we received survey responses from 162 households. Table 2 displays the balance of observables between households in the control group and households in the treated group (see Appendix B.2 for the breakdown by each treatment). With the exception of the number of children under 18 , there are no statistically significant differences between the control and treatment groups. ${ }^{11}$

\subsection{Descriptive Evidence}

Before moving to our empirical analysis, it is useful to first examine model-free evidence of the treatment effect. Figure 1 presents electricity usage by minute on average for all non-event days in our sample stratified by treatment group. Each figure shows the control group and one of the treatment groups. Panel (a) shows usage for the portal group, Panel (b) for the text message group, Panel (c) for the text message and suggested action group,

\footnotetext{
${ }^{11}$ See Appendix B.3 Table A.7 for further summary statistics on electricity consumption.
} 
and Panel (d) for the pricing group. ${ }^{12}$ For reference, the event day treatment period is shown by the shaded areas, although these figures cover only non-event days, i.e., there is no treatment occurring. For each of the panels in Figure 1 there is no clear difference between the treatment and control. We also perform a series of statistical tests, and cannot find an hour of the day where there is a significant difference between the treatment and control. ${ }^{13}$ This further reassures us that the randomization in our experiment is valid.

Figure 2 presents the same figures for critical peak event days only. Again, there are four panels, each representing one of the four treatments. A first clear finding from Figure 2 is that for all but the pricing treatment, there is very little difference in electricity consumption between the treatment and control. This is true both during treatment hours and in non-treatment hours. In fact, for all but the pricing treatment, simple statistical tests show no significant differences for any hour of the day. However, for the pricing treatment (Panel $(\mathrm{d})$ ), we see a large reduction in electricity usage during the treatment hours. Looking at the mean during the treatment period, this amounts to about a $20 \%$ reduction in usage. Notably, this reduction also appears to continue for a couple of hours after the end of the treatment period, suggesting that it takes consumers some time to re-adjust their electricity usage after the treatment period (e.g., by turning their air conditioners back on).

These results corroborate the hypotheses that the treatment effect from the online portal is minimal. However, we were surprised to also see a minimal effect from the other information treatments. Together, these figures indicate consumers do not significantly respond to information alone during normal peak period events. In contrast, we see a substantial difference between the pricing treatment group and control group, consistent with our fourth hypothesis.

Figure 3 focuses on the critical peak pricing trial, and takes advantage of the

\footnotetext{
${ }^{12}$ All panels present the residuals of a regression of electricity consumption on house fixed effects to cleanly focus on the variation we are interested in between the treatment and control.

${ }^{13}$ Specifically, we perform two-sided t-tests, and cannot find a significant difference (at the $10 \%$ level) for any hour for any of treatments. The closest is midday for the pricing treatment, but even this is not statistically significant.
} 
individually-metered appliance data, to present air conditioning use on event days for the pricing trial relative to the control trial. What is most remarkable about this figure is that it almost exactly mirrors Panel (d) of Figure 2. The treatment group and control group AC use appears to follow a nearly identical trend prior to the treatment period, followed by a large decline in the treatment group AC use during the treatment period, and this decline extends for approximately two hours after the treatment period. This descriptive evidence immediately indicates that air conditioning is playing an important role in the electricity reductions in the pricing treatment.

Figure 4 presents descriptive evidence from the off-season low-pricing experimental program, which provides initial corroborating evidence for our final hypothesis. In Panel (a) we show the mean electricity consumption for the treatment and control groups during the wind treatment months. This panel shows a dramatic and impressive degree of load-shifting for the treated group. Relative to the control group, the treated group observes a substantial increase in electricity consumption during the early morning hours (prior to $5 \mathrm{AM}$ ), followed by a substantial decrease in electricity consumption in the daylight and evening hours. As most households are not awake during the early morning hours, this almost certainly must come about from programmable electricity uses.

To provide a deeper insight into the mechanism behind these results, Panel (b) of Figure 4 shows electric vehicle electricity use for those households that have electric vehicles in either the control or treatment group. Households with electric vehicles in the control group display an increase in charging in the evening hours (when people return home from work) and a spike in charging at $10 \mathrm{PM}$, which is possibly the result of some households programming their electric vehicles to automatically charge at $10 \mathrm{PM}$. In the treatment group, we see a very strong pattern of load-shifting, with much of the electric vehicle charging occurring just before $5 \mathrm{AM}$, rather than in the evening hours. This is consistent with households programming their electric vehicles to finish charging by 5 $\mathrm{AM}$ (choosing a time to finish charging by is a standard option in electric vehicles).

This pattern of a price-induced electric vehicle load shifting towards the early morning 
hours when wholesale electricity prices are low and away from the evening hours when prices are high is to the best of our knowledge a new result. It holds great promise for pricing strategies to improve economic efficiency in a transportation system reliant on electric vehicles. When we examined other appliances or households that did not have electric vehicles, we found only very modest evidence of effects. For example, when we examined households that did not have electric vehicles, there is only a modest increase in nighttime electricity use and a modest decrease in evening electricity use, and this appears to be largely driven by heating (see Appendix C).

\section{Empirical Analysis and Results}

The descriptive evidence presented above provides a strong indication of a treatment effect from pricing, but little or no effect from the information treatments. This section more formally examines the average treatment effect of the critical peak pricing experiment using an econometric analysis, explores spillovers and mechanisms, and examines the second nighttime field experiment.

\subsection{Summer Event Treatment Effects}

We set the stage for our analysis by noting that even in the raw data, there is a statistically significant difference in means between the critical peak pricing treatment group and control group during the event periods. The critical peak pricing treatment group displays a reduction in electricity use of $0.38 \mathrm{kWh}$ per hour during the event period (a $14 \%$ decrease), and a two-sided test of this difference in means has a p-value of 0.000 . This provides initial statistical evidence supporting the fourth hypothesis that households respond to changes in peak period pricing.

We next move to a formal econometric analysis. We estimate the average treatment 
effect (ATE) for all treatments $j$ using the following linear equation:

$$
Y_{i t}=\sum_{j} \beta^{j} T_{i j t}+\mathbf{X} \boldsymbol{\gamma}+\rho_{i}+\boldsymbol{\phi}(t)+\varepsilon_{i t},
$$

where $Y_{i t}$ is the electricity usage by household $i$ in minute of the sample $t . T_{i j t}$ is a dummy variable indicating that household $i$ is in treatment group $j$ and receives the treatment in time $t$ (i.e., it is an event hour on an event day and the household is treated). $\rho_{i}$ are household fixed effects to control for unobserved heterogeneity at the household level. $\phi(t)$ is a quarter-hour of the sample fixed effect (i.e., fixed effects for each 15 minute interval of the sample) to control for time-specific demand shocks. ${ }^{14} \mathrm{X}$ is a vector containing any remaining interactions not subsumed by the fixed effects (e.g., it is an event day and the household is treated with one of the treatments, or it is a peak time and the household is treated).

Our empirical specification in (1) can be viewed as a triple-differences specification in that it exploits variation across treatment and control, across critical peak days and nonpeak days, and across treatment and non-treatment hours. Identification fundamentally relies on the randomization of the field experiment, but further benefits from comparing differences in trends in the triple-difference. We cluster standard errors at the household level to account for any pattern of household-level correlation across the residuals. ${ }^{15}$

One question this specification raises is whether there may be spillovers or loadshifting from event hours to non-event hours on an event day. Figure 2 shows a modest reduction in electricity use in the hours just after the event period ends for the pricing trial. Thus, in our preferred specification, we drop the two hours prior to the event period and the two hours after the event period. It turns out this has very little effect on our

\footnotetext{
${ }^{14}$ We thank Severin Borenstein for suggesting quarter-hour fixed effects.

${ }^{15}$ Multiple hypothesis testing (MHT) is a potential concern in all empirical work, and occasionally economists have begun adjusting for it. The statistical significance stars in our tables are based on standard tests, but we also use the Bonferroni MHT correction procedure to adjust the p-values in all of the models run in this paper, and find very few changes. All of the statistically significant coefficients in the CPP trial remain statistically significant with little change in the stars. We lose somewhat more significance in the off-peak pricing trial, but the wind trial hour-specific results still show statistically significant treatment effects in some hours.
} 
estimates. $^{16}$

Column (1) in Table 3 presents our main results from estimating Equation (1). Relative to the control group, the results show no statistically significant effects for the online portal, text message, and text message + recommendation treatments, consistent with our descriptive evidence and the simple evidence from our t-tests. ${ }^{17}$ This supports our first hypothesis, but does not support the second and third. The pricing treatment reduces electricity use, consistent with our fourth hypothesis. Our coefficient estimate indicates that pricing reduces event period electricity use by $0.39 \mathrm{kWh}$ per hour. The average hourly electricity consumption during the event hours for the control group is $2.79 \mathrm{kWh}$ per hour, so this can be seen as a $14 \%$ decrease in electricity consumption, just as in the raw data. For comparison, this decline in electricity consumption is equivalent to $\$ 8.57$ per event or $\$ 231$ across the 27 event periods.

Columns (2) and (3) of Table 3 replace $Y_{i t}$ in (1) with electricity use from major categories, as previously defined in Table 1. Column (2) shows that the reduction in electricity consumption from adjustable uses across treatments is very similar to the total reduction in column (1). ${ }^{18}$ Again, we see no statistically significant effect for any of the information treatments. The treatment effect for pricing is almost identical in columns (1) and (2), suggesting that the reduction in electricity usage can be attributed entirely to adjustable uses. Column (3) presents the results for non-adjustable uses, and it shows no statistically significant effects for any of the treatments, as would be expected by definition of this category of uses. ${ }^{19}$

Column (4) of Table 3 focuses on what we find to be the most important electricity use: air conditioning. As we showed in Table 1, air conditioning comprises $63 \%$ of electricity

\footnotetext{
${ }^{16}$ We also explore other subsamples of the data, such as removing the day before and after a treatment day when one might be worried about spillovers. We find no perceptible differences in results.

${ }^{17}$ Clustered standard errors may be somewhat conservative, so we also use Newey-West standard errors (with 60 lags based on the common $0.75 * T^{(1 / 3)}$ rule of thumb, where $T$ is the number of time periods). We find no notable changes in the statistical significance.

${ }^{18}$ Adjustable uses include all monitored lights, bathroom use, bedroom use, clothes washer use, dryer use, dining room use, dishwasher use, kitchen use and kitchen appliance use, and office use.

${ }^{19}$ The results for the "unaccounted" electricity use are similar to those for the non-adjustable category, with no statistically significant effects (See Appendix D.1)
} 
use during event days and is an adjustable electricity use, so one might expect much of the response to be from this use. Indeed, the results in column (4) show a reduction of 0.29 $\mathrm{kWh}$ per hour from air conditioning usage alone for the pricing treatment group. This result, along with the result for all electricity use, suggests that air conditioning makes up $74 \%$ of the reductions in electricity use, a slightly greater percentage than the percentage of electricity use from air conditioning on event days.

Appendix D.1 presents the results for other major electricity uses, including use from electric vehicles and unaccounted-for uses. For several other major uses, including electric vehicles, we find a negative coefficient, but we do not have sufficient power to to precisely estimate the coefficient. We view these results as indicating that the non-air conditioning reductions stem from many different electricity uses, with no single other use dominating. As before, the information treatment groups show no statistically significant treatment effects. These findings highlight the importance of air conditioning for the response to critical peak pricing in hot climates like in Austin, Texas.

Economists are often interested in calculating the price elasticity of demand for electricity use. In our context, it is possible to calculate the price elasticity at the mean for the pricing trial. For overall electricity use, the price elasticity of electricity demand is -0.03 (with a standard error of 0.01 using the delta method) and for air conditioning use only it is again -0.03 (with a standard error of 0.007 ). However, we view these elasticities very cautiously. There is evidence from two recent papers that the price elasticity of electricity use during critical peak pricing or time-of-use pricing may vary with the level of the price change (Gillian 2018; Prest 2018). ${ }^{20}$ The intuition for this finding is that critical peak pricing is salient to consumers, leading them to make changes to behavior, but in many cases, the changes in behavior do not depend on the magnitude of the price change. For instance, a consumer might be led to turn down air conditioning nearly as much for a price increase of 10 cents as a price increase of 20 cents-it is the act of remembering to turn down the air conditioner that matters the most. Thus, we interpret our -0.03 elasticity as

\footnotetext{
${ }^{20}$ Unfortunately, our experiment was run and completed before these working papers came out, so we are unable examine the effect of different price changes in our critical peak pricing.
} 
the price elasticity of electricity consumption for the roughly $\$ 0.64-\$ 0.12=\$ 0.52$ per $\mathrm{kWh}$ change in effective marginal price in our experiment, and our results do not speak to how the price elasticity might differ for different marginal price changes. However, this price elasticity of -0.03 is slightly smaller than the commonly estimated elasticity of -0.1 (e.g., Ito 2014).

We perform a series of robustness checks to confirm the above results (See Appendix D.1 for details). For example, we exploit different sources of variation and find that our results are quite robust. We also examine the results using 15-minute-level data instead of minute-level data, and find nearly identical results. We further examine the behavior of the pricing treatment group on non-event hot days above $90^{\circ} \mathrm{F}$ to confirm that households are responding to pricing and not just the hot day (for an altruistic reason perhaps). This can be thought of as a placebo test. We find statistically insignificant results, with a coefficient on the treatment of -0.14 and a standard error of 0.09 .

We next explore a robustness check where we replace the control group in our estimations with the smaller control group of 24 households elsewhere in Austin. We find similar results, although of slightly smaller magnitude (see Table A.9). This last robustness check with the Austin-wide control group suggests that our results likely have at least some external validity beyond the Mueller neighborhood. Finally, we limit the sample to households with similar demographic characteristics to Texas more broadly. We estimate our primary specification on this subsample to explore external validity relative to the rest of Texas (based on observables). Despite a reduction in sample size, the results remain consistent (see Appendix D.2).

\subsection{Spillovers and Habituation}

Figure 2 above provided suggestive evidence of a spillover reduction in electricity usage just after the event period in response to the peak pricing treatment. It is also possible there is load-shifting just prior to the event period. We can quantify such spillovers by examining the half hour just before and after the event period. We focus on the pricing 
experiment, and thus we only include the pricing and control groups in this estimation. We run the following linear regression:

$$
Y_{i t}=\sum_{j} \beta^{\text {pre }} \text { Pre }_{i j t}+\beta^{d} \text { During }_{i t}+\sum_{j} \beta^{\text {post }} \text { Post }_{i j t}+\mathbf{X} \boldsymbol{\gamma}+\rho_{i}+\boldsymbol{\phi}(t)+\epsilon_{i t},
$$

where $Y_{i t}$ is again electricity consumption for household $i$ in minute $t$, Pre $_{i j t}$ is a dummy variable for household $i$ during a 30 minute increment $j$ of the 3-4 PM pre-event period on event days, During $_{i t}$ is a dummy variable for household $i$ during the event hours of 4-7PM on event period days, and Post $t_{i j t}$ is a dummy variable for household $i$ during a 30 minute increment of the 7-8 PM post-event period on event days. The variables $\rho_{i}$ and $\phi(t)$ are household and quarter hour of the sample fixed effects as in Equation 1. $\mathrm{X}$ is again a vector containing any remaining interactions not subsumed by the fixed effects.

Table 4 shows the results of estimating Equation 2 for total electricity consumption and air conditioning electricity usage. The coefficients on the pre-period variables are positive, but are small and not statistically significant. As expected, the coefficients on the event period are nearly identical to our primary specification. What is more notable is that the coefficients on the post-event period dummies are statistically significant, consistent with the graphical evidence in Figure 2. These coefficients suggest a $0.23 \mathrm{kWh}$ per hour decrease $(7.7 \%$ decrease) in electricity use in the 30 minutes just after the end of the event period, which is almost half the size of the treatment effect during the event period. We see a somewhat smaller effect 30 minutes to one hour after the end of the event period. We also see a similar result for air conditioning use only. These findings are consistent with households being slow to turn their air conditioners back on just after the end of the event period, in contrast to the load-shifting leading to increasing electricity usage found in Harding and Lamarche (2016).

The idea that households may change their behavior over time in response to the same stimuli is well-grounded in the recent empirical literature (Allcott and Rogers 2014; Ito et al. 2018, e.g., ). We explore the possibility of habituation by examining how the primary 
treatment effects of the pricing trial change over time, from the first event month-June 2013-to the last event month-September 2014.

Table 5 presents these monthly results. Columns (1) and (2) present the results for 2013 and 2014 for total electricity consumption, while columns (3) and (4) present the results for 2013 and 2014 for air conditioning electricity consumption. Comparing columns (1) and (2) reveals a dramatic difference between 2013 and 2014. While the signs of the coefficients are negative for both years, the reductions in total electricity consumption are much greater in 2013, the first year of the experiment. In fact, for most months in 2014, the treatment effect coefficients are all closer to zero than the coefficients for the same months in 2013, and only the coefficient for September is statistically significant (p-value $<0.1$ ). We see a parallel finding for air conditioning usage in columns (3) and (4), in that the air conditioning reduction is substantially lower in 2014 than 2013, and several of the differences for a given month across the two years are statistically significant. ${ }^{21}$

These results strongly suggest some habituation to critical peak pricing, a finding that is only possible due to our research design that covers multiple years. Such habituation has important policy implications, as it suggests that the conservation that can be expected from critical peak pricing may decline over time. However, we also show that there is still a reduction in electricity use even at the end of the second year. To the best of our knowledge, these findings about habituation and continued long-run reductions from critical peak pricing are new to the literature. Previous work has suggested that social norm messaging can continue to have an effect even if used periodically over a relatively long period of time (Allcott and Rogers 2014), which suggests that for critical peak pricing to have a longer term effect, one would want to find new salient approaches to keep household's attention.

Looking across months, we see the strongest responses in June and September, despite the fact that there are fewer event days on these months. This is true for both total electricity consumption and air conditioning. One hypothesis for this finding is that the beginning and the end of the trial in each year are the most salient to households. We

\footnotetext{
${ }^{21}$ In Appendix Table A.8, we show that 2013 and 2014 were similarly hot summers on average.
} 
cannot confirm this hypothesis, but we can note that the effects by month do not appear to necessarily match with the hottest summer months (see Appendix Table A.8), which effectively rules out one other alternative hypothesis; namely, that consumers are less responsive in July and August because they feel a greater need for cooling during the hottest months.

\subsection{Further Evidence on Mechanisms}

Our rich data allows us to provide some further evidence on the mechanisms underpinning our results. We have already shown that $74 \%$ of the reduction in electricity use is from consumers turning down their air conditioner, demonstrating that the primary mechanism is air conditioning. This raises several additional questions. For instance, we showed evidence of continued reductions after the event periods that dissipated over time. One might similarly wonder whether households pre-cool homes in the hour just prior to treatment. Alternatively, it might be the case that homeowners in the pricing group leave the house altogether in response to treatment or turn down appliances while they are home.

We first examine evidence of pre-cooling. Recall that Table 4 showed no notable effect of pre-event period effects for the pricing group. To examine this more closely, we estimated Equation (2) separately for days with a "pre-cool your home" message and days with other messages message for just the sample of the text message + recommendation group and the control group. We find an increase in air conditioning consumption of 0.15 $\mathrm{kWh}$ per hour ( $\mathrm{p}$-value $<0.1$ ) on the pre-cool days for the text + recommendation group (see Appendix D.3). We see this as suggestive evidence of very modest load-shifting in response to the message, consistent with our third hypothesis, even though we do not find evidence of a statistically significant decrease during the treatment period.

We next examine whether households are actually home during the event periods, as one mechanism for conservation is that people may leave their homes during the event period. The Pecan Street survey indicates that $63 \%$ of the responding households have at 
least one member that works from home (this includes stay-at-home parents). This alone suggests that at least some of the households are likely to be at home during the event periods. We explore this further by comparing non-air conditioning adjustable appliance usage on event days and similarly hot non-event days. ${ }^{22}$ We find almost identical electricity usage for these adjustable end uses, ruling out that people leave their homes due to the high price event (see Appendix D.4).

\subsection{Night Low-Pricing Treatment Effects}

Our field experiment complements the summer pricing program with our off-peak night program, where households who were randomized into the pricing treatment group receive a text message at the beginning of each off-peak month (March, April, May, November, December) letting them know that their effective price from the hours 10 PM to 6 AM is $\$ 0.0265$ per $\mathrm{kWh}$ for that month. ${ }^{23}$ All households have programmable thermostats and it is also possible to program electric vehicles to be finished charging by a certain hour. Figure 4 provides descriptive evidence of substantial load-shifting from daytime hours to night hours, with electric vehicles being the dominant load shifted.

We now run an econometric analysis to estimate the average treatment effect. We begin by examining the effect during day hours versus night hours. Here we only include households in the pricing treatment and control group and we only include the off-peak months in our sample. We estimate the following linear equation:

$$
Y_{i t}=\sum_{h} \beta^{h} T_{i h t}+\rho_{i}+\phi(t)+u_{i t},
$$

where $Y_{i t}$ is again electricity usage by household $i$ in minute $t, T_{i h t}$ is a dummy for being a treated household during the hour of the night $h$, where $h$ is each hour over the night from 10 PM - 6 AM (or an average over several of the hours). As before, $\rho_{i}$

\footnotetext{
${ }^{22}$ Non-air conditioning adjustable appliance usage includes lights, bathroom use, bedroom use, clothes washer use, dining room use, dishwasher use, dryer use, kitchen and kitchen appliance use, living room use, and office use.

${ }^{23}$ Recall that off-peak prices were between 8 and 9 cents/kWh in 2013-14.
} 
are household fixed effects, and $\phi(t)$ are fixed effects for each 15-minute interval in the sample.

For ease of presentation, in Table 6 we present coefficients for two four-hour time frames of night hours: 10 PM - 1 AM and 2 AM - 5 AM. The choice of these time frames was motivated by Figure 4. Column (1) presents the results for all electricity uses, column (2) for electric vehicles, and column (3) for heating.

Consistent with our final hypothesis, we find an average increase in total electricity consumption in the 2AM-5AM off-peak hours of $0.13 \mathrm{kWh}$ per hour ( $\mathrm{p}$-value $<0.1)$. This is a large increase, but it is even more dramatic if we examine the increase by hour. For example, between $3 \mathrm{AM}$ and $4 \mathrm{AM}$, we see an increase of $0.19 \mathrm{kWh}$ per hour (p-value $<$ 0.05). There is also a statistically significant effect for the hours $2 \mathrm{AM}$ - 3AM that is similar in magnitude to the effect for 3 AM to 4 AM. Table A.14 in Appendix D.5 presents the results by hour.

Table 6 also shows the results for electric vehicles (column (2)) and heating (column (3)). The coefficient in column (2) indicates that $85 \%$ of the overall increase in electricity consumption during the night off-peak hours is from the charging of electric vehicles, highlighting that electric vehicles have great potential for managing electricity load. As electric vehicles become more common, this finding suggests that night low pricing will be increasingly valuable to improve economic efficiency by encouraging households to shift the charging of electric vehicles to low-cost hours. With "vehicle-to-grid" use of electric vehicle batteries for grid management, it is possible that the potential to improve economic efficiency will be even larger in the future. The heating results in column (3) are not statistically significant and are close to zero. This emphasizes that electric vehicle charging is the primary driver of our wind trial results.

\section{Welfare Implications}

The results above have important welfare implications and this section briefly explores these implications with illustrative calculations. The welfare gains possible from sum- 
mer critical peak pricing and off-peak low-pricing stem from the large deviation between marginal social costs and retail prices during these hours. For example, a recent article in Forbes pointed to wholesale electricity rates in ERCOT (the electric market for most of Texas) as high as $\$ 4,000 / \mathrm{MWh}(\$ 4 / \mathrm{kWh})$ in some locations on July $18,2018 .{ }^{24}$ This is a remarkable contrast from residential electricity prices (in 2013 of 11.4 cents/ $\mathrm{kWh}$ and in 2014 of 12.1 cents/kWh).

During our two summers, the highest average wholesale price in ERCOT in 2013 and 2014 was $\$ 740 / \mathrm{MWh}^{25}$ Assuming ERCOT is a competitive market and drawing estimates of marginal damages of air pollutants from Nick Muller's AP2 model and average marginal emissions factors (Holland et al. 2016), we calculate illustrate welfare gains (see Appendix $\mathrm{E}$ for calculation details). With a utility marginal cost of generation $\$ 740 / \mathrm{MWh}$ and our calculation of marginal damages of $\$ 25 / \mathrm{MWh}$, the marginal social cost of generation is $\$ 765 / \mathrm{MWh}$ or 76.5 cents $/ \mathrm{kWh}$. This is greater than the experimental price of 64 cents per kWh and much greater than the Austin Energy price (we use 12 cents per kWh for simplicitly).

We find that for each summer peak event period, the average social welfare benefits per peak day are $\$ 1.20$ per household. Over all 27 peak event days, this amounts to $\$ 32.38$ per household. Extrapolated to all of the households in Austin, the average gains over all 27 peak days would be $\$ 11.7$ million if all of Austin were to adopt the experimental price and respond the same way. While we may want to be cautious of extrapolating too far, if we extrapolate to all of Texas the social welfare gains are \$239 million. Most of the welfare gains are from mispricing; only about $2 \%$ of the gains are from reduced external costs.

The social welfare gains are accompanied by a reduction in consumer surplus, both from the reduced consumption and the transfer from consumers to the utility (prior to

\footnotetext{
${ }^{24}$ See https://www. forbes.com/sites/joshuarhodes/2018/07/19/ texas-electric-grid-sets-new-system-wide-all-time-peak-demand-record-twice.

${ }^{25}$ The data source can be downloaded from http://www.ercot.com/gridinfo/load/load_ hist/. Note ERCOT covers all but a small part of Texas and it includes Austin. The average wholesale price on event days is lower, but this illustrative calculation focuses on potential benefits, as wholesale prices have been continuing to rise. See Appendix for more detail.
} 
compensation). Per household over the 27 event days, this transfer amounts to $\$ 101$ and the total loss in consumer surplus is $\$ 109$ on average. In our experiment, households were compensated on average $\$ 125$ (plus a $\$ 200$ participation bonus). The utility reduces costs by about $\$ 40$ per household over the 27 event days from reducing the amount of electricity that is 'bought high and sold low,' and the utility would receive the \$101 transfer as well if the utility ran the program. This exceeds the $\$ 125$ compensation on average, suggesting a potential Pareto improvement. ${ }^{26}$

Note the $\$ 125$ compensation also covers the wind experimental program. However, in our calculations, the social welfare gains from the experimental wind price are relatively small at $\$ 2.36$ per household over all of the wind periods. Extrapolated to Austin, this would imply a gain of $\$ 851,000$. Further extrapolating to Texas implies a gain of $\$ 17$ million. These much smaller values are due to the smaller differences between the actual retail and experimental prices and the night marginal social cost (marginal damages are larger at night). However, the gains still exist and may be much larger in a future with many more electric vehicles.

\section{Conclusions}

This paper examines a field experiment with two complementary programs examining information and pricing approaches to induce a household response to changes in the marginal cost of electricity or changes in information. The first experimental program increases the marginal cost of electricity during summer peak event hours and also tests several information programs designed based on the academic literature. The second experimental program reduces the marginal cost of electricity during off-peak times when abundant wind generation in Texas drives the wholesale price of electricity down. Both are designed to improve economic efficiency by more closely aligning the retail price with the social cost of electricity provision. We also shed light on the mechanisms, using our

\footnotetext{
${ }^{26}$ This ignores the participation incentive, but if critical peak pricing was mandatory and did not involve appliance-level metering, there would be no need for a participation incentive.
} 
unique appliance-level data to provide the first evidence we are aware of on the large contribution of air conditioning to the critical peak pricing response.

While our results suggest that pricing may improve economic efficiency, we find very little evidence of a consumer response to our information treatments. We tested access to an online portal, a text message conservation appeal, and a text message conservation appeal along with a concrete recommendation, none of which led to a noticeable treatment effect. We view this null result as an indication that conservation appeals may be useful during times of crisis (Reiss and White 2008; Ito et al. 2018), and perhaps effective along with phone calls and social norms approaches (Brandon et al. 2018), but during normal summer days, such approaches alone are less likely to be effective. Indeed, some of the only evidence of an effect we found was a modest increase in electricity use prior to the event period when the text message reminder included a recommendation to "pre-cool your home," but this came along with no discernable change in electricity use during the event. One of the more important results of this study is that it is the first to demonstrate the potential for electric vehicles to load shift later into the night, effectively showing that an electric vehicle charging supply curve exists that may be used by utilities or other for-profit aggregators.

The experiment was performed on a heterogeneous neighborhood in a hot climate where many households were interested in solar energy and electric vehicles. We do not claim external validity to the entire United States. Indeed, it would be useful to perform a similar field experiment in other parts of the country. We believe that our results shed light on the effects one might expect for similar neighborhoods to the Mueller neighborhood throughout the South and Southwest of the United States. As electric vehicle penetration increases, our findings on the substantial potential for electric vehicle charging load shifting using a night low-pricing scheme will become increasingly relevant for greater parts of the country. From a policy perspective, it is useful to know where we are heading in the near future.

Our experiment also compensates households to participate in the pricing trials, and 
thus it should not be interpreted as identical to a utility-run pricing program. However, our results provide evidence of a household response to pricing that is relevant for understanding utility-run programs. Importantly, the results indicate that utilities could improve economic efficiency by instituting critical peak pricing. If designed carefully, there may even be a realized Pareto improvement, in which consumers are compensated for their lost consumer surplus while utilities also gain. Such compensation may also help build political support. Given the difficulty in implementing real-time pricing for households, which would unquestionably bring in even larger welfare benefits, this approach may be a more feasible second-best approach to improve economic efficiency. 


\section{References}

Allcott, H. (2011a), 'Rethinking real-time electricity pricing', Resource and Energy Economics $33(4), 820-842$.

Allcott, H. (2011b), 'Social norms and energy conservation', Journal of Public Economics 95(9-10), 1082-1095.

Allcott, H. (2015), 'Site selection bias in program evaluation', Quarterly Journal of Economics 130(3), 1117-1165.

Allcott, H. and Rogers, T. (2014), 'The short-run and long-run effects of behavioral interventions: Experimental evidence from energy conservation', The American Economic Review 104(10), 3003-3037.

Asensio, O. and Delmas, M. (2015), 'Nonprice incentives and energy conservation', Proceedings of the National Academy of Sciences 112(6), E510-E515.

Bollinger, B. and Hartmann, W. (2018), 'Information versus automation and implications for dynamic pricing', Working Paper .

Borenstein, S. and Holland, S. (2005), 'On the efficiency of real-time electricity pricing', RAND Journal of Economics 26(3), 93-116.

Brandon, A., Ferraro, P., List, J., Metcalfe, R., Price, M. and Rundhammer, F. (2017), 'Do the effects of social nudges persist? theory and evidence from 38 natural field experiments', NBER Working Paper 23277.

Brandon, A., List, J., Metcalfe, R., Price, M. and Rundhammer, F. (2018), 'Testing for crowd out in social nudges: Evidence from a natural field experiment in the market for electricity', Proceedings of the National Academy of Sciences forthcoming, 1-6.

Byrne, D., Nauze, A. L. and Martin, L. (2018), 'Tell me something i don't already know: Informedness and the impact of information programs', Review of Economics and Statistics 100(3), 510-527. 
Cullen, J. (2013), 'Measuring the environmental benefits of wind generated electricity', American Economic Journal: Economic Policy 5(4), 107-133.

Duflo, E. and Saez, E. (2003), 'The role of information and social interactions in retirement plan decisions: Evidence from a randomized experiment', Quarterly Journal of Economics 118(3), 815-842.

Ferraro, P. J. and Price, M. K. (2013), 'Using nonpecuniary strategies to influence behavior: Evidence from a large-scale field experiment', The Review of Economics and Statistics 95(1), 64-73.

Gillian, J. (2018), ‘Dynamic pricing, attention, and automation: Evidence from a field experiment in electricity consumption', Working Paper .

Gneezy, U., Meier, S. and Rey-Biel, P. (2011), 'When and why incentives (don't) work to modify behavior', Journal of Economic Perspectives 25(4), 191-210.

Grubb, M. and Osborne, M. (2015), 'Cellular service demand: Biased beliefs, learning, and bill shock', American Economic Review 105(1), 234-271.

Harding, M. and Lamarche, C. (2016), 'Empowering consumers through data and smart technology: Experimental evidence on the consequences of time-of-use electricity pricing policies', Journal of Policy Analysis and Management 35(4), 906-931.

Harding, M. and Sexton, S. (2017), 'Household response to time-varying electricity prices', Annual Review of Resource Economics 9, 337-359.

Harrison, G. and List, J. (2004), 'Field experiments', Journal of Economic Literature 42(4), 1009-1055.

Holland, S. P., Mansur, E. T., Muller, N. Z. and Yates, A. J. (2016), 'Are there environmental benefits from driving electric vehicles? the importance of local factors', American Economic Review 106(12), 3700-3729. 
Ito, K. (2014), 'Do consumers respond to marginal or average price? evidence from nonlinear electricity pricing', American Economic Review 104(2), 537-563.

Ito, K., Ida, T. and Tanaka, M. (2018), 'Moral suasion and economic incentives: Field experimental evidence from energy demand', American Economic Journal: Economic Policy 10(1), 240-267.

Jessoe, K. and Rapson, D. (2014), 'Knowledge is (less) power: Experimental evidence from residential energy use', The American Economic Review 104(4), 1417-1438.

Kahneman, D. and Tversky, A. (1984), 'Choices, values, and frames', American Psychologist 39(4), 341-350.

Martin, S. and Rivers, N. (2011), 'Dynamic pricing of electricity in the mid-atlantic region: Econometric results from the baltimore gas and electric company experiment', Journal of Regulatory Economics 40(1), 82-109.

Martin, S. and Rivers, N. (2018), 'Information provision, market incentives, and household electricity consumption: Evidence from a large-scale field experiment', Journal of the Association of Environmental and Resource Economists 5(1), 207-231.

Prest, B. (2018), 'Peaking interest: How awareness drives the effectiveness of time-of-use electricity pricing', RFF Working Paper .

Reiss, P. C. and White, M. W. (2008), 'What changes energy consumption? prices and public pressures', The RAND Journal of Economics 39(3), 636-663.

Rosen, S. (1974), ‘Hedonic prices and implicit markets: Product differentiation in pure competition', Journal of Political Economy 82(1), 34-55.

Wolak, F. (2006), 'Residential customer response to real-time pricing: The anaheim critical-peak pricing experiment', Stanford University Working Paper . 
Wolak, F. (2011), ‘Do residential customers respond to hourly prices? evidence from a dynamic pricing experiment', American Economic Review: Papers and Proceedings 101(3), 8387.

Wolak, F. (2013), 'An experimental comparison of critical peak and hourly pricing: The powercentsdc program', Stanford University Working Paper . 


\section{Tables \& Figures}

Table 1: Use By Major Category (Percent)

\begin{tabular}{|c|c|c|c|}
\hline Variable & Non-Summer & Summer & Event Period \\
\hline \multicolumn{4}{|c|}{ Panel A: Use by major category } \\
\hline adjustable & 39.3 & 57.9 & 72.8 \\
\hline unadjustable & 8.2 & 5.2 & 4.3 \\
\hline unmeasured & 52.4 & 36.8 & 22.9 \\
\hline \multicolumn{4}{|c|}{ Panel B: Use by major appliance } \\
\hline heating/cooling & 15.9 & 45.2 & 63.2 \\
\hline washer/dryer & 2.9 & 1.6 & 1.0 \\
\hline kitchen & 9.3 & 5.3 & 4.5 \\
\hline Electric vehicle & 4.8 & 3.0 & 1.9 \\
\hline
\end{tabular}

Notes: The values in Panel A add up to $100 \%$. "Unadjustable" refers to appliances such as refrigerators that must run all the time. "Adjustable" refers to usage from individually metered appliances that can easily be turned up and down (e.g., air conditioners, clothes washers, dryers, etc.). "Unmeasured" is the difference between total consumption and the sum of the adjustable and unadjustable individually metered usage, and it includes any appliance that does not have an individual meter. Panel B includes selected metered appliances, and thus does not add up to $100 \%$. 
Table 2: Balance of Observables

\begin{tabular}{lcccccc}
\hline \hline & \multicolumn{3}{c}{ Control } & \multicolumn{3}{c}{ Treatment } \\
& mean & std. dev. & mean & std. dev. & mean diff & p-value \\
\hline Non-event-day 4-7 PM Electric Use (kWh/hour) & 2.42 & 0.008 & 2.37 & 0.008 & 0.05 & 0.72 \\
Income (categorical) & 4.61 & 1.27 & 4.25 & 1.39 & 0.36 & 0.17 \\
Education (categorical) & 1.58 & 0.57 & 1.63 & 0.59 & -0.05 & 0.67 \\
Preferred Thermostat Temp $\left({ }^{\circ} \mathrm{F}\right)$ & 70.4 & 3.75 & 69.4 & 3.0 & 1.0 & 0.14 \\
Number of Televisions & 1.72 & 1.06 & 1.74 & 0.92 & -0.02 & 0.92 \\
1(Has Solar PV System) & 0.08 & 0.27 & 0.18 & 0.38 & -0.10 & 0.12 \\
1(Has Electric Vehicle) ${ }^{1}$ & 0.14 & 0 & 0.51 & 0 & -0.37 & 0.00 \\
1(Has programmable thermostat) & 1 & 0 & 1 & 0 & 0 & $\mathrm{~N} / \mathrm{A}$ \\
Number of Residents $_{\text {Square Footage of House }}$ & 2.44 & 1.01 & 2.53 & 1.34 & -0.09 & 0.71 \\
\hline \hline
\end{tabular}

Notes: Data on demographics was obtained from the Pecan St. survey. An observation is a household. Average income is approximately $\$ 85,000$ for treatment and control groups. Some houses only responded to certain questions, hence the number of observations varies by observable. The number of observations for each observable are as follows: $\mathrm{N}$ income $=107, \mathrm{~N}$ educ $=110$, $\mathrm{N}$ temp $=109, \mathrm{~N}$ number of televisions $=110, \mathrm{~N}$ solar $\mathrm{pv}=110, \mathrm{~N}$ residents $=99, \mathrm{~N}$ house square footage $=88 .{ }^{1} \mathrm{EV}$ is only for the pricing and control groups as we only evaluate EV use during the wind pricing trial.

Table 3: Summer Event Treatment Effects

\begin{tabular}{lcccc}
\hline \hline & $\begin{array}{c}(1) \\
\text { Electricity } \\
\text { Use }\end{array}$ & $\begin{array}{c}(2) \\
\text { adjustable } \\
\text { (include AC) }\end{array}$ & $\begin{array}{c}(3) \\
\text { nonadjustable }\end{array}$ & $\begin{array}{c}(4) \\
\text { AC only }\end{array}$ \\
\hline$\beta^{T D P j}$ coefficients & $-0.39^{* * *}$ & $-0.38^{* * *}$ & -0.001 & $-0.29^{* * *}$ \\
Pricing & $(0.10)$ & $(0.10)$ & $(0.002)$ & $(0.08)$ \\
Text + Action & -0.04 & -0.10 & -0.001 & -0.08 \\
& $(0.08)$ & $(0.08)$ & $(0.001)$ & $(0.07)$ \\
Text Message & 0.02 & -0.07 & -0.001 & 0.009 \\
& $(0.08)$ & $(0.08)$ & $(0.001)$ & $(0.06)$ \\
Portal & 0.04 & -0.003 & 0.005 & -0.02 \\
& $(0.08)$ & $(0.098)$ & $(0.003)$ & $(0.08)$ \\
\hline Household FE & $\mathrm{Y}$ & $\mathrm{Y}$ & $\mathrm{Y}$ & $\mathrm{Y}$ \\
Quarter of Sample FE & $\mathrm{Y}$ & $\mathrm{Y}$ & $\mathrm{Y}$ & $\mathrm{Y}$ \\
\hline R-squared & 0.16 & 0.09 & 0.24 & 0.06 \\
$\mathrm{~N}$ & $194 \mathrm{~m}$ & $145 \mathrm{~m}$ & $194 \mathrm{~m}$ & $145 \mathrm{~m}$ \\
\hline \hline
\end{tabular}

Notes: Dependent variable in column (1) is total electricity use, in (2) is electricity use from all adjustable appliances (e.g., air conditioners, washers, dryers, etc.), in (3) is electricity use by non-adjustable uses (e.g., refrigerators), and in (4) is electricity use by air conditioners (AC) only. Triple-difference coefficients shown; all other interactions in (1) are included. An observation is a household-minute and electricity use is in units of kWh per hour. Standard errors clustered on $i$ in parentheses. The number of observations changes in each column because not all households have everything individually-metered. ${ }^{* * *}$ denotes $\mathrm{p}<0.01$. 
Table 4: Critical Peak Pricing Spillovers

\begin{tabular}{lcc}
\hline \hline & $(1)$ & $(2)$ \\
& Total Use & AC Use \\
\hline 1 (Treated × 3:00-3:30PM Pre-Period) & -0.02 & 0.03 \\
& $(0.08)$ & $(0.07)$ \\
1 (Treated × 3:30-4:00PM Pre-Period) & -0.08 & -0.03 \\
& $(0.08)$ & $(0.07)$ \\
1 (Treated × 4:00-7:00PM Treatment Period) & $-0.40^{* * *}$ & $-0.30^{* * *}$ \\
& $(0.10)$ & $(0.08)$ \\
1 (Treated × 7:00-7:30PM Post-Period) & $-0.23^{* *}$ & $-0.18^{* * *}$ \\
& $(0.09)$ & $(0.07)$ \\
1 (Treated × 7:30-8:00PM Post-Period) & $-0.16^{*}$ & $-0.14^{* *}$ \\
& $(0.09)$ & $(0.06)$ \\
\hline Household FE & $\mathrm{Y}$ & $\mathrm{Y}$ \\
Quarter of Sample FE & $\mathrm{Y}$ & $\mathrm{Y}$ \\
\hline R-squared & 0.14 & 0.06 \\
N & $91 \mathrm{~m}$ & $74 \mathrm{~m}$ \\
\hline \hline
\end{tabular}

Notes: Dependent variable in (1) is total electricity use; in (2) is air conditioning (AC) use. Only spillover triple-difference coefficients shown; all other variables in (2) are included. An observation is a household-minute and electricity use is in units of $\mathrm{kWh}$ per hour. The number of observations declines from Table 3 because models in this table include the pricing treatment and control group only. Standard errors clustered on $i$ in parentheses. *** denotes $\mathrm{p}<0.01$, ** $\mathrm{p}<0.05,{ }^{*} \mathrm{p}<0.1$. 
Table 5: Pricing Treatment Effect By Month

\begin{tabular}{lcccc}
\hline \hline & \multicolumn{2}{c}{$(1)$} & $(2)$ & \multicolumn{2}{c}{$(3)$} & $(4)$ \\
& Total Use & \multicolumn{2}{c}{ AC Use } \\
& 2013 & 2014 & 2013 & 2014 \\
\hline 1 (Treated $\times$ June) & $-0.66^{* * *}$ & -0.13 & $-0.53^{* * *}$ & $-0.13^{* *}$ \\
& $(0.13)$ & $(0.10)$ & $(0.11)$ & $(0.06)$ \\
1 (Treated $\times$ July) & $-0.22^{*}$ & -0.083 & $-0.16^{*}$ & $-0.09^{*}$ \\
& $(0.12)$ & $(0.08)$ & $(0.09)$ & $(0.05)$ \\
1 (Treated $\times$ Aug) & $-0.29^{* *}$ & -0.11 & $-0.15^{*}$ & $-0.11^{*}$ \\
& $(0.11)$ & $(0.10)$ & $(0.08)$ & $(0.07)$ \\
1 (Treated $\times$ Sept) & $-0.38^{* * *}$ & $-0.15^{*}$ & $-0.27^{* * *}$ & $-0.10^{*}$ \\
& $(0.13)$ & $(0.08)$ & $(0.10)$ & $(0.05)$ \\
\hline Household FE & $\mathrm{Y}$ & $\mathrm{Y}$ & $\mathrm{Y}$ & $\mathrm{Y}$ \\
Quarter of Sample FE & $\mathrm{Y}$ & $\mathrm{Y}$ & $\mathrm{Y}$ & $\mathrm{Y}$ \\
\hline R-squared & 0.18 & 0.16 & 0.08 & 0.06 \\
$\mathrm{~N}$ & $96 \mathrm{~m}$ & $98 \mathrm{~m}$ & $67 \mathrm{~m}$ & $78 \mathrm{~m}$ \\
\hline \hline
\end{tabular}

Notes: Dependent variable in (1)-(2) is total electricity use; in (3)-(4) is air conditioning (AC) use. Only triple-difference coefficients shown; all other pricing ones in (1) are included. An observation is a householdminute and electricity use is in units of $\mathrm{kWh}$ per hour. The number of observations differs slightly by year due to our data covering March 2013-October 2014. Standard errors clustered on $i$ in parentheses. ${ }^{* * *}$ denotes $\mathrm{p}<0.01,{ }^{* *} \mathrm{p}<0.05,{ }^{*} \mathrm{p}<0.1$. 
Table 6: Wind Pricing Experimental Program

\begin{tabular}{lccc}
\hline \hline & $(1)$ & $(2)$ & $(3)$ \\
& Use & EV & Heating \\
\hline 1 (Treated $\times 10$ PM-1AM) & 0.02 & -0.08 & 0.03 \\
& $(0.07)$ & $(0.07)$ & $(0.05)$ \\
1 (Treated $\times 2$ AM-5AM) & $0.13^{*}$ & $0.11^{*}$ & 0.04 \\
& $(0.07)$ & $(0.06)$ & $(0.06)$ \\
\hline Household FE & $\mathrm{Y}$ & $\mathrm{Y}$ & $\mathrm{Y}$ \\
Quarter of Sample FE & $\mathrm{Y}$ & $\mathrm{Y}$ & $\mathrm{Y}$ \\
\hline R-squared & 0.15 & 0.09 & 0.10 \\
$\mathrm{~N}$ & $30 \mathrm{~m}$ & $13 \mathrm{~m}$ & $26 \mathrm{~m}$ \\
\hline \hline
\end{tabular}

Notes: Dependent variable in (1) is total electricity use, in (2) is electric vehicle use, and in (3) is heating electricity use. Only triple-difference coefficients shown; all other interactions in Equation (2) are included. An observation is a household-minute and electricity use is in units of $\mathrm{kWh}$ per hour. Regressions only include wind period hours (10 PM 6 AM) to exclude load shifting effects during non-treatment hours as evidenced by Figure 4 . Standard errors clustered on $i$ in parentheses. ${ }^{*}$ denotes $\mathrm{p}<0.01$. 


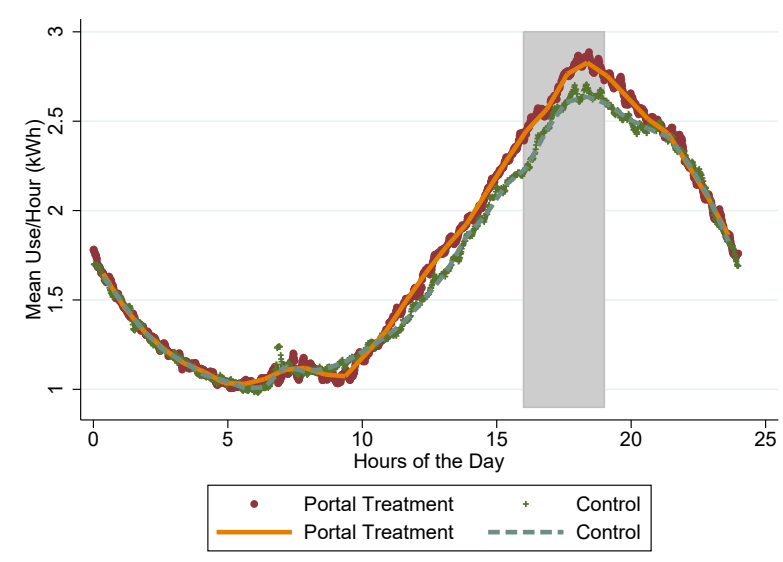

(a) Portal Treatment

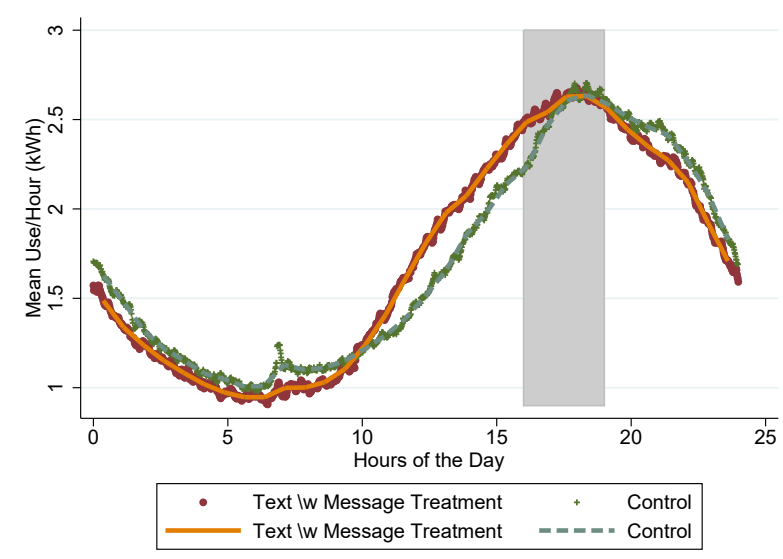

(c) Text w/ Message Treatment

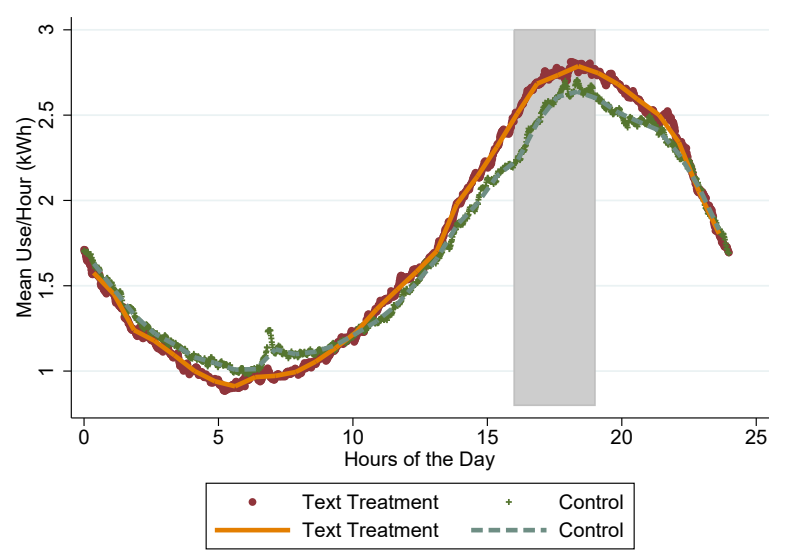

(b) Simple Text Message Treatment

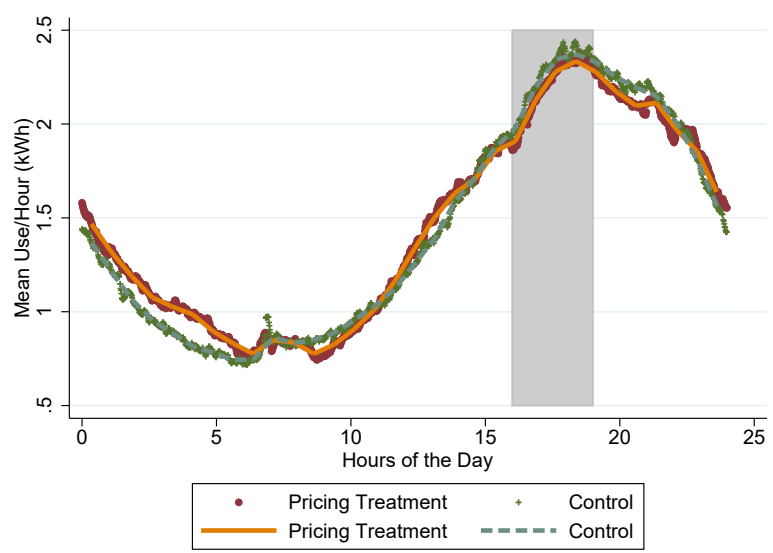

(d) Pricing Treatment

Figure 1: The plots display non-event day mean minute level use by treatment group. The series plotted are the residuals after conditioning on household fixed effects. 


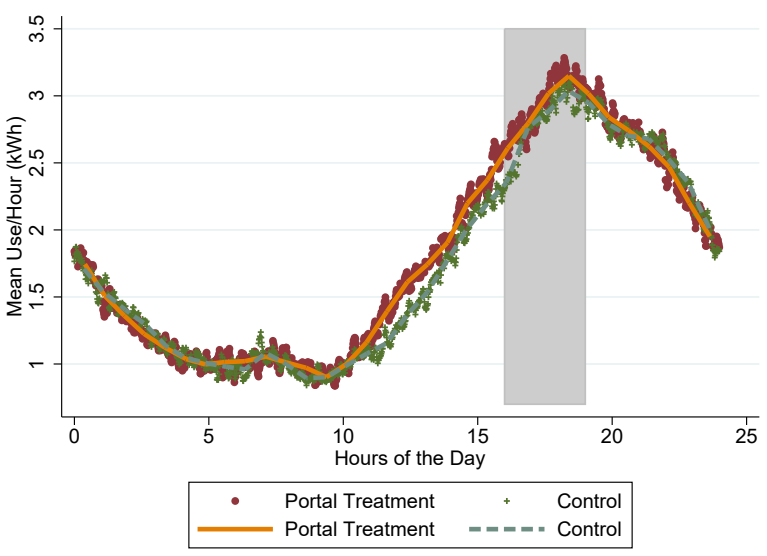

(a) Portal Treatment

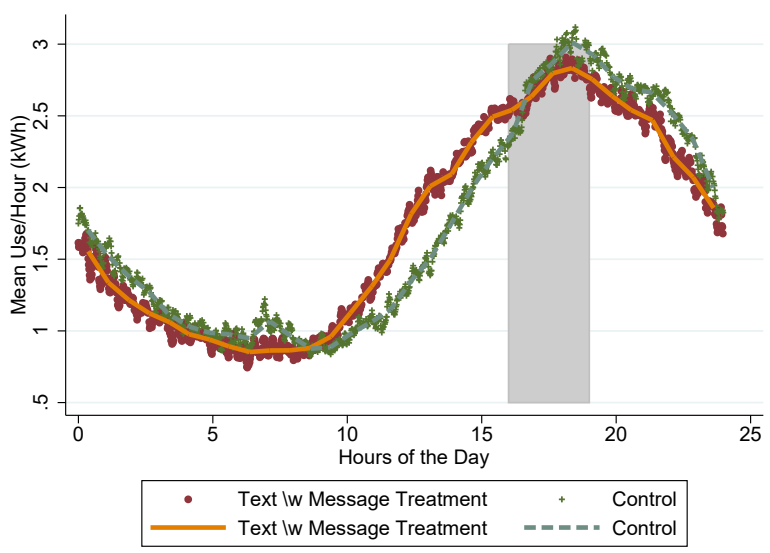

(c) Text w/ Message Treatment

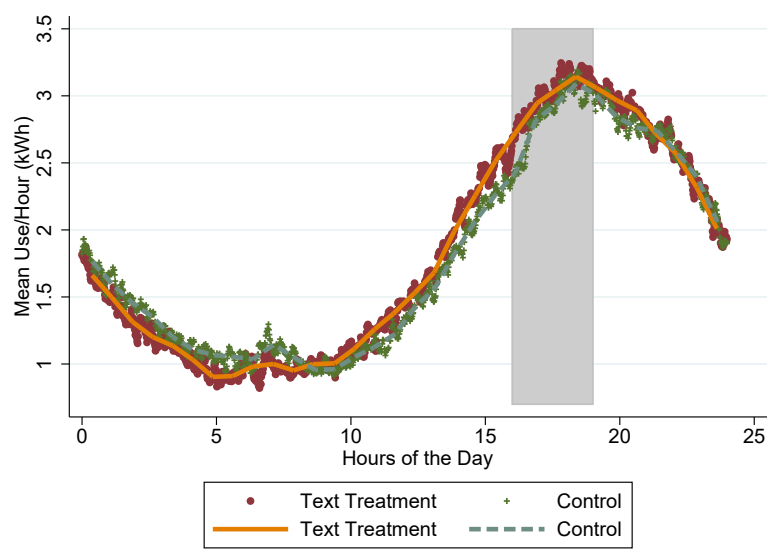

(b) Simple Text Message Treatment

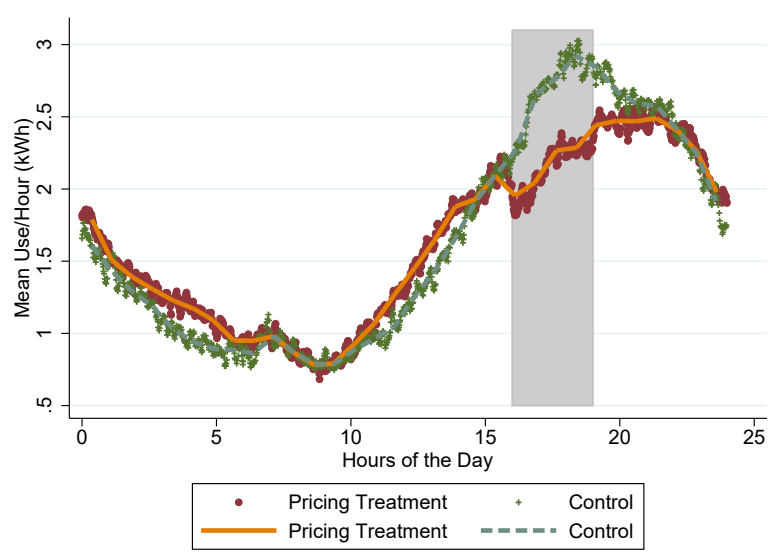

(d) Pricing Treatment

Figure 2: The plots display event day mean minute level use by treatment group. The series plotted are the residuals after conditioning on household fixed effects. 


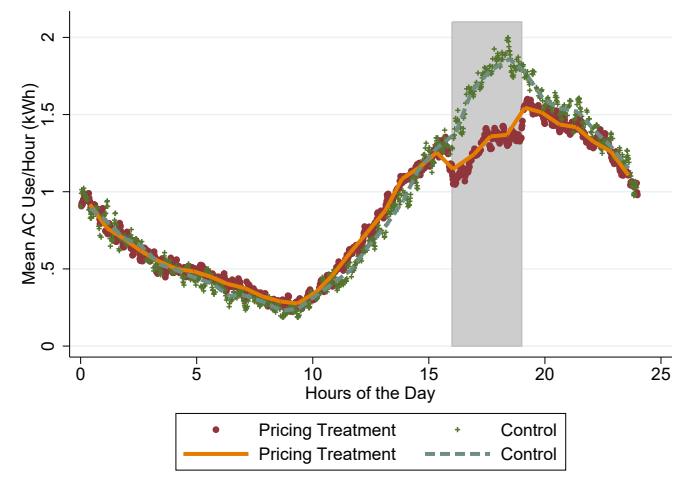

Figure 3: The plot displays event day mean minute level air conditioning (AC) use for the pricing treatment and control groups. The series plotted are the residuals after conditioning on household fixed effects.

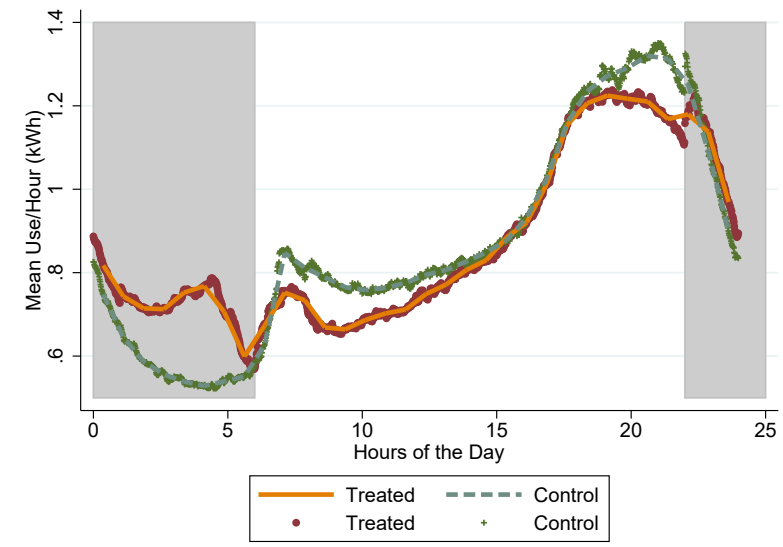

(a) Total Use

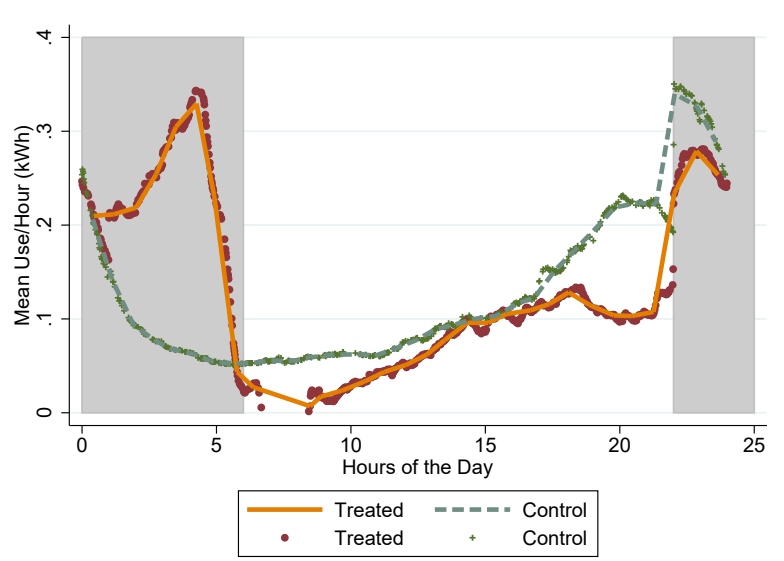

(b) Electric Vehicle Use

Figure 4: The plots display event period mean minute level total use and electric vehicle use for the night low pricing treatment and control groups. The series plotted are the residuals after conditioning on household fixed effects. 


\section{ONLINE APPENDIX}

\section{A Further Details of the Field Experiment}

This short appendix provides further details of the field experiment. We begin with with the language for the pricing trial recruitment invitation:

Sign up now to take part in Pecan Street's electricity pricing trial! Pecan Street is conducting an experiment among its residential volunteers to determine whether, and to what extent, consumers are willing to alter electricity use by time of day. As a member of Pecan Street's research in Mueller, your participation is particularly valuable to this study and can enable you to earn up to $\$ 700$.

Unlike most pricing trials, you will not be billed at a different rate by Austin Energy for participating. You will see your electricity bill unchanged by this study and will continue to be billed according to Austin Energy's existing rate structure. Instead, you will receive 1. a base credit of at least $\$ 150$ and 2. monthly credits based on your household's response to an experimental electric rate that decreases late in the day to encourage nighttime electricity use and increases on predetermined days in the summer months.

Follow the pricing schedule and save based on these experimental rates? A monthly credit will be added to your base credit to be paid in full at the conclusion of the study, which can total up to $\$ 700$. Opt not to follow the schedule and use electricity as usual? You will not be penalized and will owe no additional money to Austin Energy.

Next we provide an example of what a circuit-level meter looks like: 


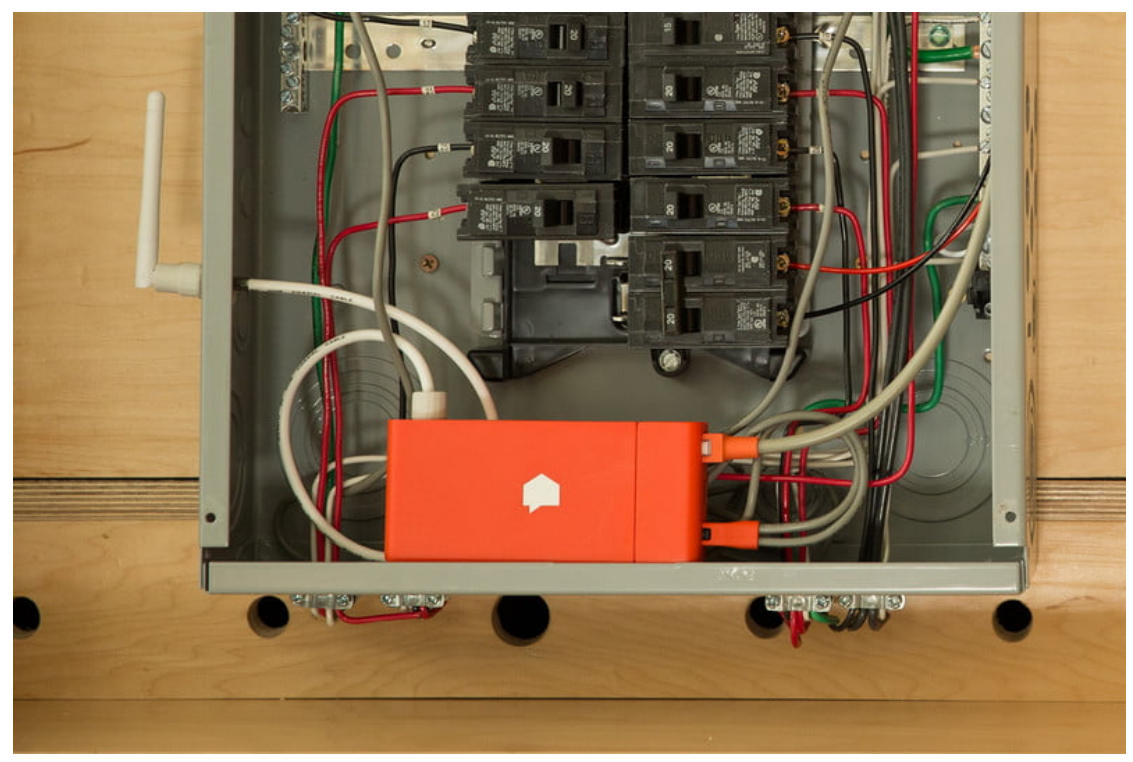

We also present a map of the Mueller neighborhood:

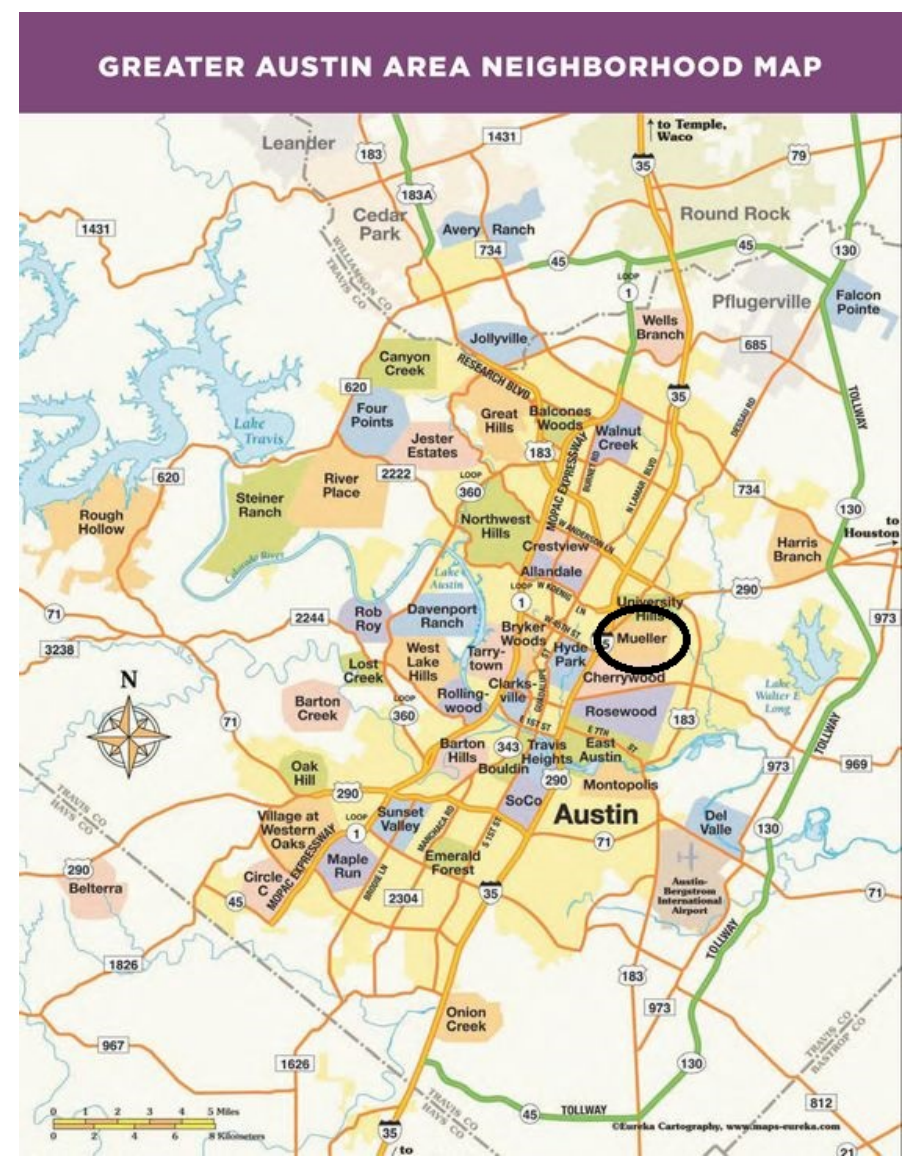

Figure A.1: Map of Austin and the Mueller Neighborhood 
Finally, in Table A.1, we provide a comparison of demographic characteristics for the Mueller neighborhood with the broader city of Austin. It is not possible to formally test for differences using the aggregate Census data so in the final column of the table, we indicate whether the reported margins of error overlap. The margins of error overlap for income, unemployment rates, the fraction of the population with a high school diploma or more, the fraction of residents over 18 , and the number of rooms per household. The margins of error do not overlap for the fraction of residents with more than a bachelors degree or the median home value.

Table A.1: Mueller Neighborhood and Broader Austin

\begin{tabular}{|c|c|c|c|c|c|}
\hline & \multicolumn{2}{|r|}{ Austin } & \multicolumn{2}{|c|}{ Mueller Neighborhood } & \multirow{2}{*}{$\begin{array}{c}\text { Margins of } \\
\text { Error Overlap }\end{array}$} \\
\hline & Estimate & Margin of Error & Estimate & Margin of Error & \\
\hline Median Household Income & $\$ 55,216$ & $\pm \$ 908$ & $\$ 62,175$ & $\pm \$ 7,742$ & Yes \\
\hline Unemployment Rate & $5 \%$ & $\pm 0.2 \%$ & $3.2 \%$ & $\pm 2.4 \%$ & Yes \\
\hline \% High School Graduate or Higher & $87 \%$ & $\pm 0.4 \%$ & $91.4 \%$ & $\pm 6.7 \%$ & Yes \\
\hline \% Bachelor's Degree or Higher & $46 \%$ & $\pm 0.5 \%$ & $64.9 \%$ & $\pm 8.1 \%$ & No \\
\hline$\%$ Residents over 65 & $7.3 \%$ & $\pm 0.1 \%$ & $4.8 \%$ & $\pm 0.8 \%$ & No \\
\hline$\%$ Residents over 18 & $21.8 \%$ & $\pm 0.2 \%$ & $19.5 \%$ & $\pm 5.1 \%$ & Yes \\
\hline Median Value Owner-Occupied Housing Units & $\$ 227,800$ & $\pm \$ 1,975$ & $\$ 379,200$ & $\pm \$ 33,782$ & No \\
\hline Median Rooms Per House & 4.7 & \pm 0.1 & 4.1 & \pm 0.7 & Yes \\
\hline
\end{tabular}

Notes: Data source is the U.S. Census 2014 American Community Survey.

\section{A.1 Austin Energy Normal Electricity Charges}

Austin Energy was on a tiered rate schedule in 2013 and 2014. Households were charged a fixed per $\mathrm{kWh}$ rate plus a per $\mathrm{kWh}$ rate that increased with usage (an increasing block pricing system). Furthermore, all households were charged a flat $\$ 10$ fee for being connected to the service. The rates were as follows:

Total fixed per kWh charges:

- 4.654 cents/kWh in 2013

- 5.168 cents/kWh in 2014

The summer and winter tiers did not change between 2013 and 2014. The \$10 flat fee also did not change. For reference, the summer and winter tiers are presented in Table A.2. 
Table A.2: Austin Energy Pricing Tiers (cents/kWh)

\begin{tabular}{lcc}
\hline \hline Tier & Winter & Summer \\
\hline Tier 1: 0-500 kWh & 1.8 & 3.3 \\
Tier 2: $501-1000 \mathrm{kWh}$ & 5.6 & 8 \\
Tier 3: 1001-1500 kWh & 7.2 & 9.1 \\
Tier 4: $1501-2500 \mathrm{kWh}$ & 8.4 & 11 \\
Tier 5: $>$ 2500 kWh & 9.6 & 11.4 \\
\hline \hline
\end{tabular}

The average monthly use for pricing treatment households in 2013 and 2014 during treatment months was $1034.897 \mathrm{kWh}$ in 2013 and $1139.964 \mathrm{kWh}$ in 2014. Thus, the average total electricity bill was $\$ 117.8397$ per month or $\$ 0.1138$ per $\mathrm{kWh}$ in 2013 and $\$ 138.1501$ per month or $\$ 0.1212$ per $\mathrm{kWh}$ in 2014. For reference, the CPP experimental price was $\$ 0.64 / \mathrm{kWh}$ and the wind period experimental price was $\$ 0.0265 / \mathrm{kWh}$.

\section{B Further Data Description}

\section{B.1 Data Cleaning Procedure}

In this subsection we outline the data cleaning process. We downloaded the raw minute level electricity consumption data from the Pecan Street Dataport website. ${ }^{27}$ Academics can apply for free access to the data. In our regressions, we drop observations in which use by any appliance is larger than $10 \mathrm{kWh}$ per minute or use is negative. This drops $0.29 \%$ of the total observations.

For some observations, appliance-specific consumption is missing in the raw data. We do not set these values to zero. Instead, we leave them as missing. This is why, for example, the number of observations in the air conditioning regressions reported in Table 3 is less than the number of observations in the total electricity use regressions.

\footnotetext{
${ }^{27}$ Website can be found here: https://dataport.cloud/
} 


\section{B.2 Additional Tables of Balance}

This subsection of the appendix provides more detailed tables of balance comparing each of the individual treatments to the control group. Just as in Table 2, they provide evidence of successful randomization.

Table A.3: Balance of Observables for Pricing Treatment

\begin{tabular}{lccccc}
\hline \hline & \multicolumn{2}{c}{ Control } & \multicolumn{3}{c}{ Treatment } \\
& mean & std. dev. & mean & std. dev. & mean diff \\
\hline Income (categorical) & 4.61 & 1.27 & 4.41 & 1.32 & 0.19 \\
Education (categorical) & 1.58 & 0.57 & 1.73 & 0.45 & -0.15 \\
Preferred Thermostat Temp $\left({ }^{\circ} \mathrm{F}\right)$ & 70.38 & 3.75 & 69.52 & 2.99 & 0.86 \\
Number of Televisions & 1.72 & 1.06 & 1.43 & 0.73 & 0.28 \\
1(Solar PV System) & 0.08 & 0.27 & 0.27 & 0.45 & $-0.19^{*}$ \\
Number of Residents & 2.44 & 1.01 & 2.54 & 1.53 & -0.10 \\
Square Footage of House & 1888 & 611 & 2017 & 615 & -128 \\
\hline \hline
\end{tabular}

Notes: There are 30 houses in the pricing group that responded to most of the questions on the survey. The remainder are control houses. Some houses only responded to certain questions, hence the number of observations varies by observable. The number of observations for each observable are as follows: $\mathrm{N}$ income $=80 ; \mathrm{N}$ educ $=83 ; \mathrm{N}$ temp $=83 ; \mathrm{N}$ number of televisions $=82 ; \mathrm{N}$ solar $\mathrm{pv}=83 ; \mathrm{N}$ residents $=76 ; \mathrm{N}$ house square footage $=53$. If present, statistical differences would be denoted by ${ }^{* * *}$ denotes $\mathrm{p}<0.01,{ }^{* *} \mathrm{p}<0.05,{ }^{*} \mathrm{p}<0.1$. 
Table A.4: Balance of Observables for Portal Treatment

\begin{tabular}{lccccc}
\hline \hline & \multicolumn{3}{c}{ Control } & \multicolumn{2}{c}{ Treatment } \\
& mean & std. dev. & mean & std. dev. & mean diff \\
\hline Income (categorical) & 4.61 & 1.27 & 4.43 & 1.81 & 0.18 \\
Education (categorical) & 1.58 & 0.57 & 1.57 & 0.53 & 0.01 \\
Preferred Thermostat Temp $\left({ }^{\circ} \mathrm{F}\right)$ & 70.38 & 3.75 & 69.57 & 2.57 & 0.81 \\
Number of Televisions & 1.72 & 1.06 & 2.00 & 1.15 & -0.28 \\
1(Solar PV System) & 0.08 & 0.27 & 0.00 & 0 & 0.08 \\
Number of Residents & 2.44 & 1.01 & 2.67 & 1.37 & -0.23 \\
Square Footage of House & 1888 & 611 & 2254 & 912 & -365 \\
\hline \hline
\end{tabular}

Notes: There are 7 houses in the portal group that responded to most of the questions on the survey. The remainder are control houses. Some houses only responded to certain questions, hence the number of observations varies by observable. The number of observations for each observable are as follows: $\mathrm{N}$ income $=58 ; \mathrm{N}$ educ $=60 ; \mathrm{N}$ temp $=60 ; \mathrm{N}$ number of televisions $=60 ; \mathrm{N}$ solar $\mathrm{pv}=60$; $\mathrm{N}$ residents $=56 ; \mathrm{N}$ house square footage $=36$. If present, statistical differences would be denoted by ${ }^{* * *}$ denotes $\mathrm{p}<0.01,{ }^{* *} \mathrm{p}<0.05,{ }^{*} \mathrm{p}<0.1$.

Table A.5: Balance of Observables for Text Treatment

\begin{tabular}{lccccc}
\hline \hline & \multicolumn{3}{c}{ Control } & \multicolumn{3}{c}{ Treatment } & \\
& mean & std. dev. & mean & std. dev. & mean diff \\
\hline Income (categorical) & 4.61 & 1.27 & 4.13 & 1.55 & 0.48 \\
Education (categorical) & 1.58 & 0.57 & 1.63 & 0.74 & -0.04 \\
Preferred Thermostat Temp $\left({ }^{\circ} \mathrm{F}\right)$ & 70.38 & 3.75 & 69.38 & 3.29 & 1.00 \\
Number of Televisions & 1.72 & 1.06 & 2.50 & 1.07 & $-0.78^{*}$ \\
1(Solar PV System) & 0.08 & 0.27 & 0.00 & 0.00 & 0.08 \\
Number of Residents & 2.44 & 1.01 & 2.13 & 1.64 & 0.32 \\
Square Footage of House & 1888 & 611 & 2177 & 799 & -288 \\
\hline \hline
\end{tabular}

Notes: There are 8 houses in the text group that responded to most of the questions on the survey. The remainder are control houses. Some houses only responded to certain questions, hence the number of observations varies by observable. The number of observations for each observable are as follows: $\mathrm{N}$ income $=59 ; \mathrm{N}$ educ $=61 . \mathrm{N}$ temp $=61 ; \mathrm{N}$ number of televisions $=61 ; \mathrm{N}$ solar $\mathrm{pv}=61$; $\mathrm{N}$ residents $=58 ; \mathrm{N}$ house square footage $=37$. If present, statistical differences would be denoted by ${ }^{* * *}$ denotes $\mathrm{p}<0.01,{ }^{* *} \mathrm{p}<0.05,{ }^{*} \mathrm{p}<0.1$. 


\section{B.3 Additional Summary Statistics}

This subsection of the appendix provides additional summary statistics.

Table A. 8 provides the average temperature per month per year on critical peak treatment days. 
Table A.6: Balance of Observables for Text with Message

\begin{tabular}{lccccc}
\hline \hline & \multicolumn{3}{c}{ Control } & \multicolumn{3}{c}{ Treatment } \\
& mean & std. dev. & mean & std. dev. & mean diff \\
\hline Income (categorical) & 4.61 & 1.27 & 3.83 & 1.27 & $0.78^{*}$ \\
Education (categorical) & 1.58 & 0.57 & 1.42 & 0.79 & 0.17 \\
Preferred Thermostat Temp $\left({ }^{\circ} \mathrm{F}\right)$ & 70.38 & 3.75 & 69.08 & 3.48 & 1.29 \\
Number of Televisions & 1.72 & 1.06 & 1.83 & 0.84 & -0.12 \\
1(Solar PV System) & 0.08 & 0.27 & 0.17 & 0.39 & -0.09 \\
Number of Residents & 2.44 & 1.01 & 2.78 & 1.30 & -0.34 \\
Square Footage of House & 1888 & 611 & 1919 & 632 & -30 \\
\hline \hline
\end{tabular}

Notes: There are 9 houses in the text group that responded to most of the questions on the survey. The remainder are control houses. Some houses only responded to certain questions, hence the number of observations varies by observable. The number of observations for each observable are as follows: $\mathrm{N}$ income $=63 ; \mathrm{N}$ educ $=65 ; \mathrm{N}$ temp $=65 ; \mathrm{N}$ number of televisions $=65 ; \mathrm{N}$ solar $\mathrm{pv}=65$; $\mathrm{N}$ residents $=59 ; \mathrm{N}$ house square footage $=37$. If present, statistical differences would be denoted by ${ }^{* * *}$ denotes $\mathrm{p}<0.01,{ }^{* *} \mathrm{p}<0.05,{ }^{*} \mathrm{p}<0.1$. 
Table A.7: Average Total Electricity Usage by Treatment Group by Minute (kWh)

\begin{tabular}{|c|c|c|c|c|c|}
\hline & mean & std. dev. & $\min$ & $\max$ & $\mathrm{N}$ \\
\hline \multicolumn{6}{|c|}{ Panel A: Summer } \\
\hline Pricing & 1.63 & 1.73 & 0 & 10.0 & $19,456,889$ \\
\hline Portal & 2.02 & 1.91 & 0 & 10.0 & $14,023,059$ \\
\hline Text Message & 1.84 & 1.72 & 0 & 10.0 & $13,038,821$ \\
\hline Text+Action & 1.86 & 1.85 & 0 & 10.0 & $14,606,830$ \\
\hline Control & 1.62 & 1.77 & 0 & 10.0 & $17,253,418$ \\
\hline \multicolumn{6}{|c|}{ Panel B: Non-Summer } \\
\hline Pricing & 0.95 & 1.33 & 0 & 10.0 & $28,852,697$ \\
\hline Portal & 1.11 & 1.27 & 0 & 10.0 & $21,207,853$ \\
\hline Text Message & 1.02 & 1.24 & 0 & 10.0 & $18,730,037$ \\
\hline Text+Action & 1.03 & 1.24 & 0 & 10.0 & $21,539,833$ \\
\hline Control & 0.84 & 1.14 & 0 & 10.0 & $25,132,252$ \\
\hline \multicolumn{6}{|c|}{ Panel C: Critical Peak Pricing Event Period } \\
\hline Pricing & 2.41 & 2.05 & 0 & 10.0 & 270,802 \\
\hline Portal & 3.39 & 2.11 & 0 & 10.0 & 194,079 \\
\hline Text Message & 3.10 & 1.85 & 0 & 10.0 & 180,309 \\
\hline Text+Action & 3.14 & 2.10 & 0 & 10.0 & 200,125 \\
\hline Control & 2.79 & 2.01 & 0 & 10.0 & 240,186 \\
\hline \multicolumn{6}{|c|}{ Panel D: Wind Period } \\
\hline Pricing & 0.86 & 1.16 & 0 & 10.0 & $6,349,544$ \\
\hline Portal & 0.86 & 1.04 & 0 & 10.0 & $4,735,425$ \\
\hline Text Message & 0.80 & 0.99 & 0 & 10.0 & 4,217,009 \\
\hline Text+Action & 0.82 & 1.04 & 0 & 10.0 & $4,876,809$ \\
\hline Control & 0.66 & 0.95 & 0 & 10.0 & $5,573,616$ \\
\hline
\end{tabular}

Notes: Summary statistics for electricity use (in units of $\mathrm{kWh} /$ hour) over the entire time frame of the experiment. An observation is a household-minute. We dropped values above $10 \mathrm{kWh}$ per minute and below $0 \mathrm{kWh}$ per minute $(0.29 \%$ of the total number of observations). 
Table A.8: Maximum Temperatures on Treatment Days in Celsius

\begin{tabular}{lccc}
\hline \hline & 2013 & 2014 & Both \\
\hline June & 38.02 & 34.18 & 36.48 \\
& $(3)$ & $(2)$ & $(5)$ \\
July & 35.26 & 36.55 & 36.12 \\
& $(2)$ & $(4)$ & $(6)$ \\
August & 37.01 & 35.74 & 36.38 \\
& $(5)$ & $(5)$ & $(10)$ \\
September & 34.67 & 32.31 & 33.10 \\
& $(2)$ & $(4)$ & $(6)$ \\
\hline \hline
\end{tabular}

Notes: This table presents the average daily maximum temperature on treatment days by month. Column 1 is for 2013 only, column 2 is for 2014 only, and column 3 is both years pooled. The number of treatment days in each month is reported in parentheses below the temperatures. 


\section{Further Wind Treatment Figures}

In this section we present additional wind period graphs. The first, Figure A.2 displays the wind pricing experimental period figure, similar to Figure 4a, but for houses without an electric vehicle. The second, Figure A.3 presents the wind pricing experimental period figure for heating electricity use only.

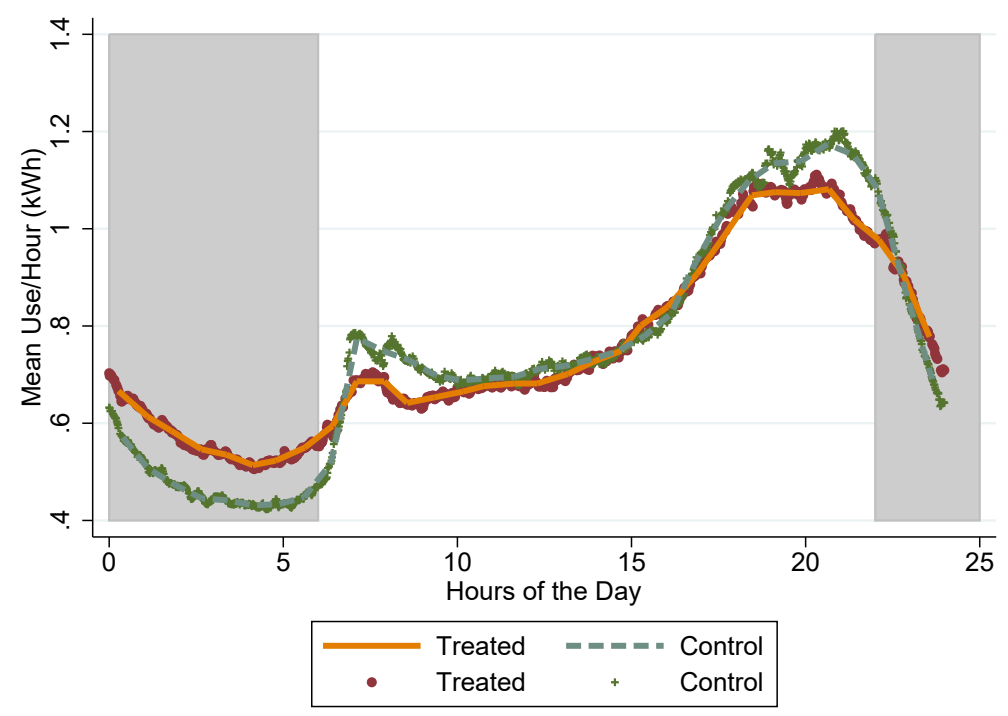

Figure A.2: Wind pricing treatment use for houses $\mathrm{w} /$ out electric vehicles. The series plotted are the residuals after conditioning on household fixed effects. 


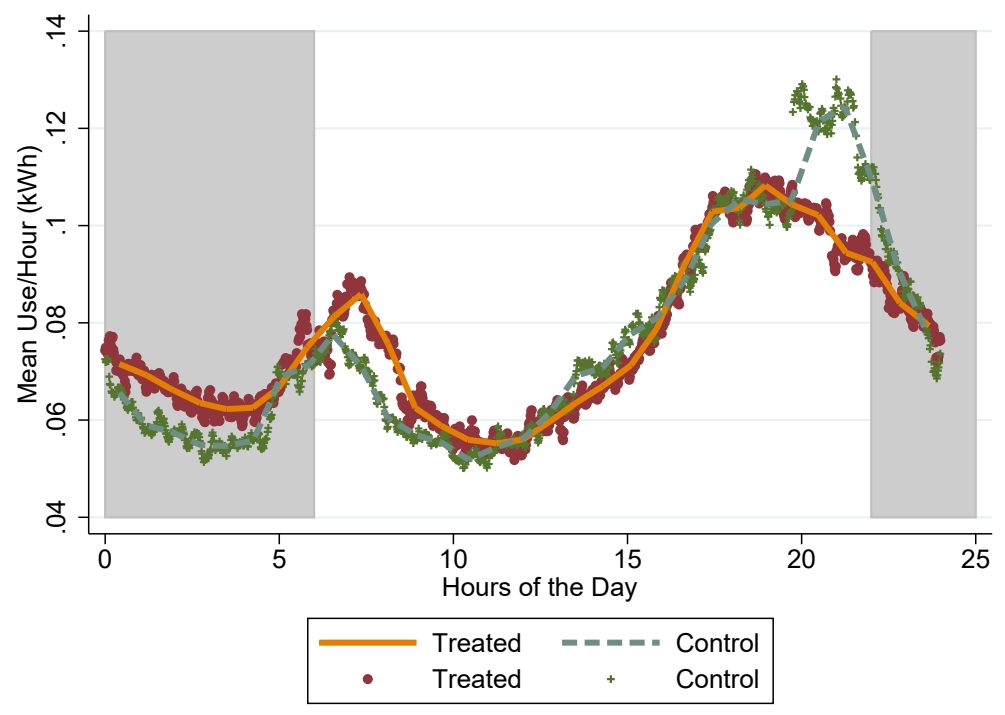

Figure A.3: Wind pricing treatment heating use. The series plotted are the residuals after conditioning on household fixed effects. 


\section{Robustness Checks and External Validity}

\section{D.1 Robustness Checks}

In this appendix subsection, we present several additional robustness checks.

First, we examine our results in a diff-in-diff specification where we exploit only two sources of variation: the differences across the treatment and control and the differences across event minutes and non-event minutes. Recall that the preferred specification also uses variation from differences across event days and non-event days. If one was worried that event days are systematically different than non-event days, one would not want to rely on this variation. Thus, we estimate Equation (1) using data only from event days. Column 1 of Table A.9 displays the results of estimating our primary model restricted to the sample of event days. The estimated coefficient of -0.42 is very slightly larger than our preferred specification in Table 3, but is quite similar and is again statistically significant.

Second, recall that in our preferred specification, we dropped the two hours prior and immediately after the summer event periods. To examine how important this assumption is, we explore a specification where we do not drop the two hours prior to the event period. The results are reported in Column 2 of Table A.9 and are virtually identical to our primary estimates.

Third, we estimate our primary model after taking the natural $\log$ of the dependent variable. The results are reported in Column 3 of Table A.9. The estimated coefficient indicates that the pricing treatment reduces electricity consumption by approximately $31 \%$ during the peak hours.

Fourth, we examine the robustness of our results to using a different control group. Recall that Pecan Street, Inc also collected minute-level usage data for an additional 24 households in Austin outside of the Mueller neighborhood. These houses were not informed of the critical peak pricing study and were not receiving any other treatment at this time, and thus serve as a useful second control group as well as providing insight into the external validity of our results. We estimate our primary model replacing the original 
control group with these additional 24 houses. The results are presented in Column 4 of Table A.9. Again, the treatment effect is somewhat smaller, but broadly consistent with the primary treatment effect reported in Table 3. We prefer our larger control group to this alternative control group.

Table A.9: Robustness: Primary Treatment Effects

\begin{tabular}{lcccc}
\hline \hline & $(1)$ & $(2)$ & $(3)$ & $(4)$ \\
& $\begin{array}{c}\text { Electricity } \\
\text { Use DiD }\end{array}$ & $\begin{array}{c}\text { Electricity } \\
\text { Use }\end{array}$ & $\begin{array}{c}\text { Log(Elect } \\
\text { Use) }\end{array}$ & $\begin{array}{c}\text { Alternative } \\
\text { Control }\end{array}$ \\
\hline Portal & 0.20 & 0.04 & -0.06 & 0.13 \\
& $(0.14)$ & $(0.08)$ & $(0.05)$ & $(0.09)$ \\
Text Message & 0.10 & 0.02 & -0.03 & 0.11 \\
& $(0.12)$ & $(0.08)$ & $(0.05)$ & $(0.09)$ \\
Text + Action & 0.09 & -0.04 & $-0.08^{*}$ & 0.05 \\
& $(0.13)$ & $(0.08)$ & $(0.04)$ & $(0.09)$ \\
Pricing & $-0.42^{* * *}$ & $-0.39^{* * *}$ & $-0.31^{* * *}$ & $-0.31^{* * *}$ \\
& $(0.15)$ & $(0.09)$ & $(0.06)$ & $(0.11)$ \\
\hline Household FE & $\mathrm{Y}$ & $\mathrm{Y}$ & $\mathrm{Y}$ & $\mathrm{Y}$ \\
Quarter of Sample FE & $\mathrm{Y}$ & $\mathrm{Y}$ & $\mathrm{Y}$ & $\mathrm{Y}$ \\
\hline R-squared & 0.16 & 0.16 & 0.30 & 0.17 \\
$\mathrm{~N}$ & $8.7 \mathrm{~m}$ & $194 \mathrm{~m}$ & $191 \mathrm{~m}$ & $159 \mathrm{~m}$ \\
\hline \hline
\end{tabular}

Notes: Column 1 displays diff-in-diff estimates of estimating (1) only on the sample restricted to event days. Column 2 is our primary treatment effects specification dropping observations that occurred 1-2 hours after the CPP treatment. Column 3 displays the primary specification with logged overall use as the outcome variable. Column 4 uses an alternative control group consisting of houses in the greater Austin area. Only triple-difference coefficients shown; all other interactions are included in the regressions. An observation is a household-minute and electricity use is in units of kWh per hour. Standard errors clustered on $i$ in parentheses. ${ }^{*}$ denotes $\mathrm{p}<0.1$.

Next, we estimate the summer peak pricing treatment effects for electric vehicle electricity usage and all unaccounted usage. Recall that unaccounted use is defined as the total use minus the use from all measured appliances (including air conditioners and electric vehicles). Table A.10 presents the results. We find that the critical peak pricing experiment did not appear to impact electric vehicle or unaccounted electricity use.

We now move on to examine our results using 15-minute level data, rather than minute-level data. One might argue that the variation at the minute level is too fine 
and too prone to measurement error and thus aggregating to the 15-minute level is preferred. The coefficients are roughly identical to the coefficients in Table 3 only divided by 15 . For example, the coefficient on total electricity use in column (1) is -6.06 and $-6.06 / 15=-0.40$, which is almost exactly our coefficient using the minute level data. 
Table A.10: Effect of Summer Peak Pricing on Further Appliances

\begin{tabular}{lcccccc}
\hline \hline & $\begin{array}{l}\text { Electric } \\
\text { Vehicle }\end{array}$ & Unaccounted & Washer & Dryer & Bathroom & Livingroom \\
\hline Portal & -0.007 & 0.01 & -0.06 & -0.01 & 0.04 & 0.05 \\
& $(0.03)$ & $(0.05)$ & $(0.04)$ & $(0.01)$ & $(0.05)$ & $(0.14)$ \\
Text Message & -0.03 & 0.001 & 0.03 & 0.003 & 0.07 & 0.22 \\
& $(0.03)$ & $(0.05)$ & $(0.04)$ & $(0.01)$ & $(0.11)$ & $(0.15)$ \\
Text + Action & -0.02 & -0.05 & -0.04 & -0.01 & 0.003 & 0.07 \\
& $(0.03)$ & $(0.04)$ & $(0.04)$ & $(0.01)$ & $(0.03)$ & $(0.19)$ \\
Pricing & -0.008 & -0.06 & -0.03 & -0.01 & 0.01 & 0.09 \\
& $(0.03)$ & $(0.04)$ & $(0.03)$ & $(0.01)$ & $(0.02)$ & $(0.12)$ \\
\hline Household FE & $\mathrm{Y}$ & $\mathrm{Y}$ & $\mathrm{Y}$ & $\mathrm{Y}$ & $\mathrm{Y}$ & $\mathrm{Y}$ \\
Quarter of Sample FE & $\mathrm{Y}$ & $\mathrm{Y}$ & $\mathrm{Y}$ & $\mathrm{Y}$ & $\mathrm{Y}$ & $\mathrm{Y}$ \\
\hline R-squared & 0.03 & 0.32 & 0.27 & 0.23 & 0.35 & 0.55 \\
$\mathrm{~N}$ & $80 \mathrm{~m}$ & $78 \mathrm{~m}$ & $82 \mathrm{~m}$ & $97 \mathrm{~m}$ & $37 \mathrm{~m}$ & $36 \mathrm{~m}$ \\
\hline \hline
\end{tabular}

Notes: This table replicates the primary treatment effect specification only with electric vehicles usage and unaccounted usage as the dependent variables. Unaccounted usage is total consumption minus consumption by all measured appliances. An observation is a household-minute and electricity use is in units of kWh per hour. Standard errors clustered on $i$ in parentheses.

Table A.11: Robust: Summer Event Treatment Effects with 15 Minute Level Data

\begin{tabular}{lcccc}
\hline \hline & $\begin{array}{c}(1) \\
\text { Electricity } \\
\text { Use }\end{array}$ & $\begin{array}{c}(2) \\
\text { AC only }\end{array}$ & $\begin{array}{c}(3) \\
\text { adjustable } \\
\text { include AC) }\end{array}$ & $\begin{array}{c}(4) \\
\text { nonadjustable }\end{array}$ \\
\hline Portal & 0.43 & -0.63 & -0.49 & 0.07 \\
Text Message & $(1.27)$ & $(1.07)$ & $(1.32)$ & $(0.05)$ \\
& 0.04 & -0.03 & -0.85 & -0.01 \\
Text + Action & $(1.23)$ & $(0.95)$ & $(1.15)$ & $(0.02)$ \\
& -0.80 & -0.95 & -1.14 & -0.008 \\
Pricing & $(1.18)$ & $(0.96)$ & $(1.17)$ & $(0.02)$ \\
& $-6.06^{* * *}$ & $-3.06^{* * *}$ & $-4.15^{* * *}$ & -0.009 \\
Household FE & $(1.48)$ & $(1.06)$ & $(1.30)$ & $(0.003)$ \\
Quarter of Sample FE & $\mathrm{Y}$ & $\mathrm{Y}$ & $\mathrm{Y}$ & $\mathrm{Y}$ \\
\hline R-squared & $\mathrm{Y}$ & $\mathrm{Y}$ & $\mathrm{Y}$ & $\mathrm{Y}$ \\
$\mathrm{N}$ & 0.22 & 0.14 & 0.20 & 0.26 \\
\hline \hline
\end{tabular}

Notes: Triple-difference coefficients shown; all other interactions in (1) are included. An observation is a household-15 minute interval and electricity use is in units of kWh per hour. Standard errors clustered on $i$ in parentheses. The number of observations changes in each column because not all households have each category individually-metered. ${ }^{* *}$ denotes $\mathrm{p}<0.05$. 


\section{D.2 External Validity}

External validity is a key question about our study. Recall that Table A.1 above compares census block data from the Mueller neighborhood to Austin more broadly. While one can never fully claim external validity without running an experiment in multiple places, we perform a test to explore whether these discrepancies matter based on observables. Specifically, we limit the sample to houses with similar incomes and education levels to the Texas average. The average income in Texas is $\$ 57,051$ according to the US Census. The Pecan Street household surveys report categorical income categories. We select all houses in the $\$ 50,000-\$ 74,999$ income category. $89.7 \%$ of the Texas population has less than a graduate degree. We further limit our sample to households with a Bachelors degree or less. We then estimate our primary results table (Table 3) using this subsample of data. The results for the pricing trial are presented in Table A.12. Importantly, the results are generally consistent with the main findings. 
Table A.12: Summer Event Treatment Effects on Census Sample

\begin{tabular}{lcccc}
\hline \hline & $\begin{array}{c}(1) \\
\text { Electricity } \\
\text { Use }\end{array}$ & $\begin{array}{c}(2) \\
\text { AC only }\end{array}$ & $\begin{array}{c}(3) \\
\text { adjustable } \\
\text { (include AC) }\end{array}$ & $\begin{array}{c}(4) \\
\text { nonadjustable }\end{array}$ \\
\hline Pricing & $-0.44^{* * *}$ & $-0.37^{* * *}$ & $-0.41^{* *}$ & -0.002 \\
& $(0.14)$ & $(0.10)$ & $(0.15)$ & $(0.001)$ \\
\hline Household FE & $\mathrm{Y}$ & $\mathrm{Y}$ & $\mathrm{Y}$ & $\mathrm{Y}$ \\
Quarter of Sample FE & $\mathrm{Y}$ & $\mathrm{Y}$ & $\mathrm{Y}$ & $\mathrm{Y}$ \\
\hline R-squared & 0.11 & 0.04 & 0.12 & 0.31 \\
$\mathrm{~N}$ & $12 \mathrm{~m}$ & $11 \mathrm{~m}$ & $11 \mathrm{~m}$ & $11 \mathrm{~m}$ \\
\hline \hline
\end{tabular}

Notes: This table replicates the primary results table limiting to households with similar income and education characteristics as Texas as a whole. The median household income in Texas is $\$ 57,051$ according to the US Census. The Pecan Street household surveys have categorical income brackets. We select all houses in the $\$ 50,000-\$ 74,999$ income category and below. Also, $89.7 \%$ of the Texas population has less than a graduate degree. We limit to households with Bachelors degrees or less. The number of houses included in each sub-treatment group is as follows: control $=6$, portal $=1$, text $=1$, text with action message $=2$, pricing $=5$. Because of the extremely low sample size for the 3 information treatments, we only show the pricing treatment results. Triple-difference coefficients shown; all other interactions in (1) are included. An observation is a household-minute and electricity use is in units of $\mathrm{kWh}$ per hour. Standard errors clustered on $i$ in parentheses. The number of observations changes in each column because not all households have each category individually-metered. *** denotes $\mathrm{p}<0.01,{ }^{* *} \mathrm{p}<0.05$. 


\section{D.3 Pre-cooling Suggestive Results}

This subsection presents a table of the suggestive results for pre-cooling. Column (1) is statistically significant at the $10 \%$ level and suggests a $0.15 \mathrm{kWh}$ per minute increase in air conditioning consumption during the pre-cooling hours for the households that received the pre-cooling text message. Column (2) presents the coefficient for the treated households during the non-event days, which is not statistically significant. However, the coefficient is positive, at 0.07 , so we view this result as only suggestive.

Table A.13: Treatment Effect on Pre-Cool Days from 2-4 PM

\begin{tabular}{|c|c|c|}
\hline \multirow{4}{*}{$\beta^{T D P j}$ coefficients } & (1) & (2) \\
\hline & $\mathrm{AC}$ & $\mathrm{AC}$ \\
\hline & Use (kWh) & Use (kWh) \\
\hline & Pre-Cool Message & non-Event-Days \\
\hline \multirow[t]{2}{*}{ Text + Action } & $0.15^{*}$ & 0.07 \\
\hline & $(0.08)$ & $(0.04)$ \\
\hline Household FE & $\mathrm{Y}$ & $\mathrm{Y}$ \\
\hline Quarter of Sample FE & $\mathrm{Y}$ & $\mathrm{Y}$ \\
\hline R-squared & 0.06 & 0.06 \\
\hline $\mathrm{N}$ & $126 \mathrm{~m}$ & $137 \mathrm{~m}$ \\
\hline
\end{tabular}

Notes: Only triple-difference coefficients shown; all other pricing ones in (1) are included. An observation is a household-minute and electricity use is in units of $\mathrm{kWh}$ per hour. Standard errors clustered on $i$ in parentheses. * denotes $\mathrm{p}<0.1$. 


\section{D.4 Are People Home? Adjustable Use on Summer Event Days}

An important question is whether or not residents were home and thus able to respond to price changes during the critical peak event periods. If people simply left their house during the event hours and used electricity elsewhere, then the residential electricity reductions may be offset by reductions elsewhere. In the Pecan Street survey, one of the questions asks if people worked from home. $62 \%$ of surveyed houses have at least one person that works from home, which could include stay-at-home parents. This suggests that many people should be home during the event periods, but it is still possible that people leave because of the events.

To further provide evidence that residents are at home during the event periods, we graph the average adjustable appliance use per treatment group on critical peak event days and similarly hot summer days. Adjustable appliances include lights, bathroom use, bedroom use, clothes washer use, dining room use, dishwasher use, dryer use, kitchen and kitchen appliance use, living room use, and office use. If people actually leave their homes during the high price event periods in order to reduce electricity use and save money, we would expect to see a difference in the use of all of these appliances. Figure A.4 shows the adjustable use on event days and similarly hot $\left(>90^{\circ}\right)$ non-event days The gray shaded area is the experimental pricing period. The two lines are pretty much on top of each other, ruling out that people leave their homes during the event periods. 


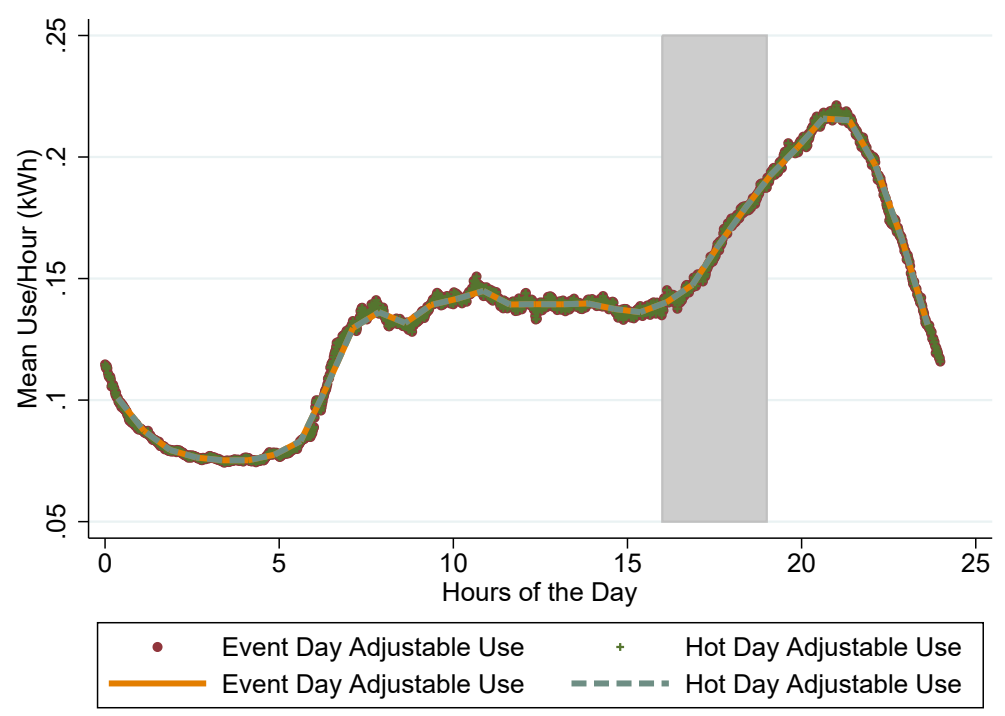

Figure A.4: This figure displays the mean adjustable use on event days and similarly hot non-event days for pricing treatment and control groups. The series plotted are the residuals after conditioning on household fixed effects.

\section{D.5 Wind Pricing Trial Estimates By Hour}

This subsection examines estimates from the wind pricing trial by hour of the night, providing additional information than Table 6 . We see similar results, but with greater statistical significance during a few key morning hours. 
Table A.14: Wind Pricing Trial Experiment

\begin{tabular}{lccc}
\hline \hline & $(1)$ & $(2)$ & $(3)$ \\
& Use & EV & Heating \\
\hline 1 (Treated $\times 10 \mathrm{PM}-11 \mathrm{PM})$ & -0.06 & -0.16 & 0.01 \\
& $(0.10)$ & $(0.13)$ & $(0.04)$ \\
1 (Treated $\times 11 \mathrm{PM}-12 \mathrm{AM})$ & 0.03 & -0.11 & 0.03 \\
& $(0.09)$ & $(0.11)$ & $(0.05)$ \\
$1($ Treated $\times 12 \mathrm{AM}-1 \mathrm{AM})$ & 0.03 & -0.06 & 0.04 \\
& $(0.07)$ & $(0.07)$ & $(0.06)$ \\
$1($ Treated $\times 1 \mathrm{AM}-2 \mathrm{AM})$ & 0.08 & 0.03 & 0.05 \\
& $(0.07)$ & $(0.07)$ & $(0.06)$ \\
$1($ Treated $\times 2 \mathrm{AM}-3 \mathrm{AM})$ & 0.12 & 0.09 & 0.04 \\
& $(0.07)$ & $(0.07)$ & $(0.06)$ \\
$1($ Treated $\times 3 \mathrm{AM}-4 \mathrm{AM})$ & $0.18^{* *}$ & $0.16^{*}$ & 0.04 \\
& $(0.08)$ & $(0.09)$ & $(0.06)$ \\
1 (Treated $\times 4 \mathrm{AM}-5 \mathrm{AM})$ & $0.19^{* *}$ & $0.18^{*}$ & 0.04 \\
& $(0.09)$ & $(0.10)$ & $(0.06)$ \\
$1($ Treated $\times 5 \mathrm{AM}-6 \mathrm{AM})$ & 0.05 & 0.02 & 0.05 \\
& $(0.08)$ & $(0.07)$ & $(0.07)$ \\
\hline Household FE & $\mathrm{Y}$ & $\mathrm{Y}$ & $\mathrm{Y}$ \\
Quarter of Sample FE & $\mathrm{Y}$ & $\mathrm{Y}$ & $\mathrm{Y}$ \\
\hline R-squared & 0.14 & 0.10 & 0.09 \\
$\mathrm{~N}$ & $30 \mathrm{~m}$ & $26 \mathrm{~m}$ & $13 \mathrm{~m}$ \\
\hline \hline
\end{tabular}

Notes: Only triple-difference coefficients shown; all other interactions in Equation (2) are included. 'Use' refers to total electricity consumption; ' $E V$ ' refers to electric vehicle electricity consumption. An observation is a household-minute and electricity use is in units of kWh per hour. Regressions only include wind period hours (10 PM - 6 AM) to exclude load shifting effects during non-treatment hours as evidenced by Figure $4 a$. Standard errors clustered on $i$ in parentheses. ${ }^{* *}$ denotes $\mathrm{p}<0.05$. ${ }^{*}$ denotes $\mathrm{p}<0.01$. 
Table A.15: Wind Pricing Experimental Program: Control Period = Jan, Feb

\begin{tabular}{lccc}
\hline \hline & $(1)$ & $(2)$ & $(3)$ \\
& Use & EV & Heating \\
\hline 1(Treated $\times 1$ 10PM-1AM) & -0.02 & 0.08 & -0.02 \\
& $(0.06)$ & $(0.11)$ & $(0.02)$ \\
1 (Treated $\times 2$ AM-5AM) & $0.08^{*}$ & $0.26^{* * *}$ & -0.01 \\
& $(0.05)$ & $(0.07)$ & $(0.02)$ \\
\hline Household FE & $\mathrm{Y}$ & $\mathrm{Y}$ & $\mathrm{Y}$ \\
Quarter of Sample FE & $\mathrm{Y}$ & $\mathrm{Y}$ & $\mathrm{Y}$ \\
\hline R-squared & 0.15 & 0.07 & 0.07 \\
$\mathrm{~N}$ & $18 \mathrm{~m}$ & $7.2 \mathrm{~m}$ & $15 \mathrm{~m}$ \\
\hline \hline
\end{tabular}

Notes: Only triple-difference coefficients shown; all other interactions in Equation (2) are included. 'Use' refers to total electricity consumption, 'EV' electric vehicle consumption, and 'Heating' consumption. An observation is a household-minute and electricity use is in units of $\mathrm{kWh}$ per hour. Regressions only include wind period hours (10 PM - 6 AM) and months 1-5 and 10-12 to exclude load shifting effects during non-treatment hours as evidenced by Figure 4 . Standard errors clustered on $i$ in parentheses. ${ }^{*}$ denotes $\mathrm{p}<0.01$. 


\section{E Illustrative Welfare Calculations}

This section outlines the back-of-the-envelope welfare calculations presented in Section 5. Given that our primary specification in (1) is a linear model, we simplify by assuming a linear demand curve. We begin with the critical peak pricing experimental program and then move to the wind experimental program.

As a starting point, consider that the Austin Energy summer electric rate in 2013 was 11.4 cents / kWh and in 2014 was 12.1 cents / kWh. Thus, regardless of the wholesale price, households are charged this rate. The 64 cents $/ \mathrm{kWh}$ charge was set prior to the summer of 2013 and was based on historical spikes in the wholesale price in the electricity nodes around Austin. On average, one would expect this critical peak pricing charge to capture the wholesale electricity rates. Using data from the Electric Reliability Council of Texas (ERCOT), ${ }^{28}$ we note that there are wholesale price spikes during the event periods, but these were not always the most expensive wholesale prices in those two summers, which suggests that the event periods were not always called in the most needed times. The peak wholesale prices in 2013 and 2014 were about \$740/MWh (74 cents / kWh). Since then the spikes have gotten even more pronounced in Texas, with rates as high as $\$ 4,000 / \mathrm{MWh}$, as noted in Section 5. Thus, as a reasonable estimate for what the potential welfare gains of critical peak pricing might be, we use 74 cents / $\mathrm{kWh}$ for our calculations.

In our illustrative calculations, we take the wholesale price as a measure of the marginal cost of generation of electricity. This assumption holds assuming that ERCOT is a competitive market. This assumption is common in the literature Cullen (e.g., 2013). Then, for simplicity, we assume that the cost of the transmission and distribution system is a sunk cost. This is reasonable in the short-run, but given that the system is built out for peak load, it is quite possible that we are underestimating the long-run benefits by making this assumption. For our calculations, we also download estimates of the marginal

\footnotetext{
${ }^{28}$ ERCOT data are publicly available from http: //www.ercot.com/gridinfo/load/load_hist/ index.html and http://mis.ercot.com/misapp/GetReports.do?report TypeId=13061\& reportTitle=Historical $\% 20 \mathrm{RTM} \div 20 \mathrm{Load} \div 20 \mathrm{Z}$ ne $\% 20$ and $\% 20 \mathrm{Hub} \% 20 \mathrm{Prices} \& \mathrm{showHTMLView}=$ \&mimickey.
} 


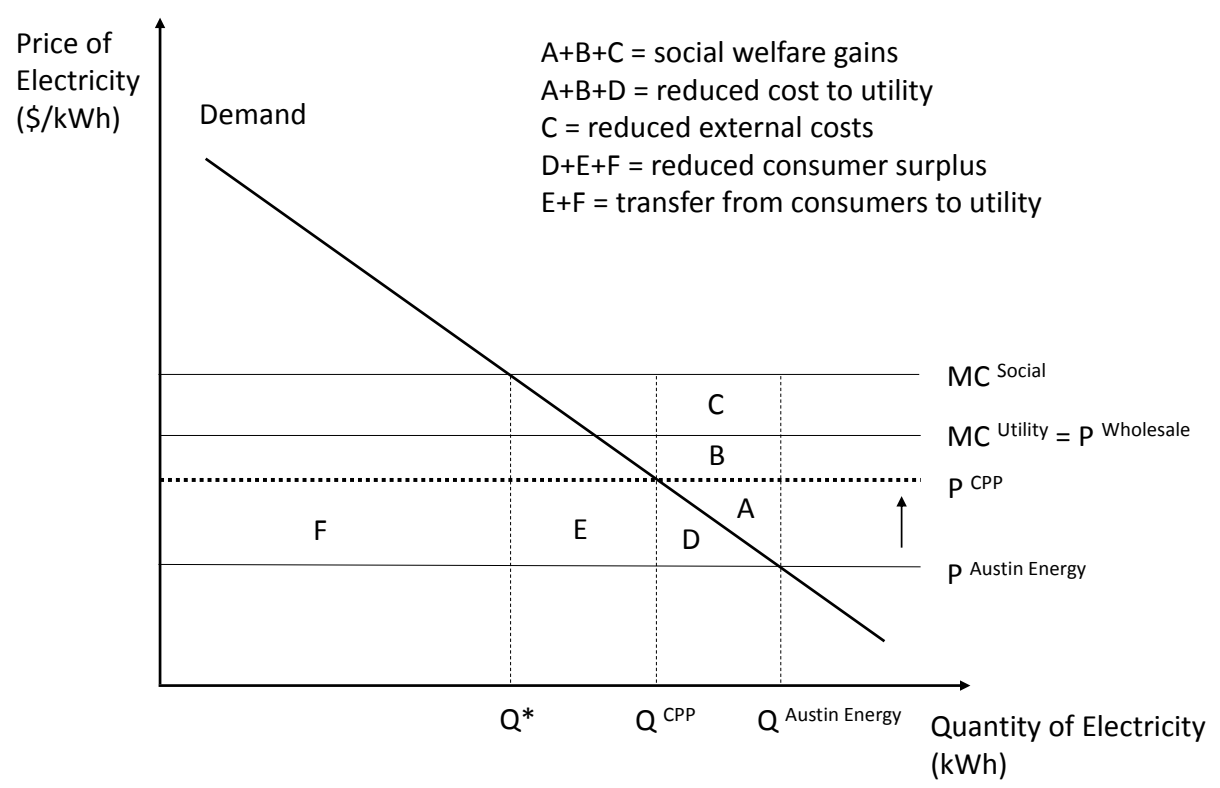

Figure A.5: Welfare Illustration When CPP Price is Below Marginal Social Cost

damages by hour from air pollution in Texas from the AP2 model (Holland et al. 2016). ${ }^{29}$ From ERCOT, we download the marginal emissions factors of electricity generation in Texas. Combined these allow us to calculate the marginal damages reduced per $\mathrm{kWh}$ of electricity consumption avoided.

Under these assumptions, the marginal social cost of electricity is still above the experimental critical peak pricing rate, although the experimental rate is much closer than the Austin Energy retail tariff. For making our next set of calculations, it is illustrative to refer to Figure A.5 showing the different changes in welfare in a stylized graph. This figure shows the social welfare gains from reducing electricity consumption during the event hours when the marginal social cost of electricity is above the retail tariff. It also shows what the transfers would be from consumers to the utility (the utility itself ran the critical peak pricing program instead of Pecan Street). Not shown are any transfers to consumers to incentivize participation.

We calculate each of the areas in Figure A.5 using the pricing treatment effect coeffi-

\footnotetext{
${ }^{29}$ We recognize that some of the externalities may be partly internalized, but reducing the marginal damages makes little difference to our results.
} 
cient estimate of -0.39 from Table 3 and the average electricity use by the control group during the full event period of $2.79 \mathrm{kWh}$ per hour from Table A.7. For a single household and single event period, we find that the social welfare gains are $\$ 1.20$, the transfer from consumers to the utility is $\$ 3.74$ (note this may possibly be compensated lump sum), the reduced consumer surplus including the transfer is $\$ 4.05$, and the reduced external costs are 3 cents. We obtain the results in the text in Section 5 by multiplying by the 27 event days, multiplying by the number of households in Austin (361,257 from Census data), or multiplying by the number of households in Texas (7.4 million from Census data). Extrapolating to all of Austin or all of Texas deserves the caveat that consumers in these broader regions would be responding in the same was as the pricing treatment households in our study and would be facing similar prices. So we recommend readers take these with a grain of salt.

For the off-peak wind program, we perform a similar analysis. The experimental price for the wind trial was again set based on the wholesale price in the electricity market nodes around Austin. It was set to 2.65 cents $/ \mathrm{kWh}$ instead of the Austin Energy winter electric rate of 8.7 cents/kWh in 2013 and 8.9 cents/ kWh in 2014. Using ERCOT data, we found that the average wholesale price in ERCOT during the night hours during the event months in those two years was 3.1 cents $/ \mathrm{kWh}$. As the marginal electricity generation at night in Texas is often coal, we calculated marginal damages of 3.2 cents $/ \mathrm{kWh}$. Under the assumption of a competitive market, this would imply a marginal social cost of electricity of 6.3 cents $/ \mathrm{kWh}$.

Using our coefficient estimate from Table 6 of 0.13 and the average electricity use by the control group during the wind period of $0.66 \mathrm{kWh}$ per hour, we calculate the social welfare gains. Figure A.6 breaks down the welfare changes due to the wind treatment into components in a stylized graph.

In our calculations, we find that the social welfare gains are roughly cent per day, or approximately $\$ 2.40$ over the ten months of the experiment (5 months in 2013 and 5 in 2014). The reason the gains are so small is that the price differences are not very large. 


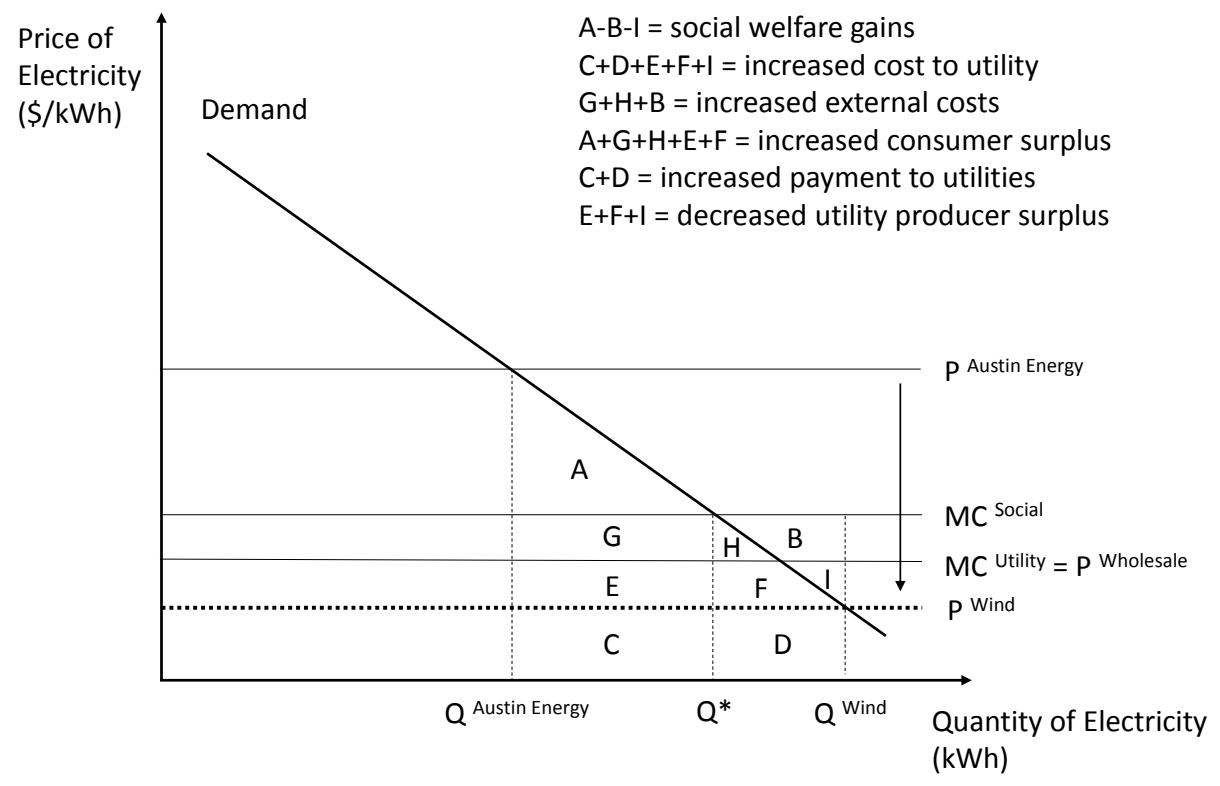

Figure A.6: Welfare Illustration For the Off-peak Experimental Program

If we extrapolate out to all of Austin, this implies social welfare gains of $\$ 851,000$, and extrapolated out to all ERCOT we are talking about \$17 million. So, there is some scope for efficiency gains, but not nearly as large as the scope for efficiency gains from critical peak pricing.

We finally emphasize that these welfare calculations are illustrative and that the exact welfare results from any given policy would vary depending on the policy. 